\title{
The concept, approach, and future research of hydrological connectivity and its assessment at multiscales
}

\author{
Yinghu Zhang ${ }^{1,2,3} \cdot$ Chenyang Huang ${ }^{1,2,3} \cdot$ Wenqi Zhang ${ }^{1,2,3} \cdot$ Jinhong Chen ${ }^{1,2,3} \cdot$ Lu Wang $^{1,2,3}$
}

Received: 19 March 2021 / Accepted: 19 August 2021 / Published online: 30 August 2021

(C) The Author(s), under exclusive licence to Springer-Verlag GmbH Germany, part of Springer Nature 2021

\begin{abstract}
In this review, we explore the concept, approach, and future research of hydrological connectivity and its assessment at multiscales, because according to the literature, an integrated review upon hydrological connectivity is lack. Systematic studies illustrate the effects of (i) human activities (i.e., dam construction, groundwater extraction, water flow regulation and diversion, and land management) and (ii) natural factors (i.e., climate, soil characteristics, vegetation, and topography) on hydrological connectivity. Approaches (i.e., soil water content patterns, runoff patterns and processes, numerical models, and index of hydrological connectivity) applied to evaluate hydrological connectivity are examined in detail. Lastly, hydrological connectivity at multiscales is indicated. This review concludes with a discussion of potential research trends that can improve understanding of hydrological connectivity. Reported records showed that few studies were published on hydrological connectivity from 1980 to 2003, whereas the evolution of these studies is temporally promising since 2003. We cannot define a standard concept of hydrological connectivity that works in all environments. We desire to show different concepts of hydrological connectivity in different environments. The degree and nature of hydrological connectivity are not static due to the influences of human activities and changes of natural factors. The index of hydrological connectivity and numerical models are the most significant approaches to assess the changes in hydrological connectivity. This study showed that considering hydrological connectivity in socialeconomical-ecological-hydrological frameworks can prevent its negative effects on surface or subsurface water quantity and quality and is beneficial for sound water sources management.
\end{abstract}

Keywords Hydrological connectivity $\cdot$ Hillslopes $\cdot$ Surface water $\cdot$ Groundwater $\cdot$ Soil macropores $\cdot$ Soil matrix

\section{Introduction}

Hydrological connectivity is used to refer to water-mediated transfer of matter, energy, and organisms within or between elements of hydrological cycles (Pringle 2001). Two elements

Responsible editor: Xianliang Yi

Yinghu Zhang

zhangfan2012oo@163.com

1 Collaborative Innovation Center of Sustainable Forestry in Southern China of Jiangsu Province, Nanjing Forestry University,

Nanjing 210037, People's Republic of China

2 Jiangsu Provincial Key Laboratory of Soil Erosion and Ecological Restoration, Nanjing Forestry University, Nanjing 210037, People's Republic of China

3 Priority Academic Program Development of Jiangsu High Education Institutions (PAPD), Nanjing Forestry University, Nanjing 210037, People's Republic of China of hydrological connectivity have been identified: structural connectivity and functional connectivity (Bracken and Croke 2007; Turnbull et al. 2008). Structural connectivity refers to the spatial patterns of elements in the landscapes, such as the spatial distribution of landscape units and physical characteristics of the catchments (Lexartza-Artza and Wainwright 2009). Different land management, i.e., wetlands (Dong et al. 2021), agricultural catchments (Sun et al. 2021), and forestry patches (Mayor et al. 2019), may reflect different spatial patterns of structural connectivity. Functional connectivity refers to how these spatial patterns affect ecohydrology (Turnbull et al. 2008). Functional connectivity is challenging to assess. Descriptors of functional connectivity mainly include the frequency, the duration, the timing, and the rate of exchanges of different water bodies (Lane et al. 2009). Implying the interaction between structural connectivity and functional connectivity (Fig. 1) is key to understanding the changes in hydrological connectivity (Bracken and Croke 2007; Turnbull et al. 2008). Such can lead to the changes of 

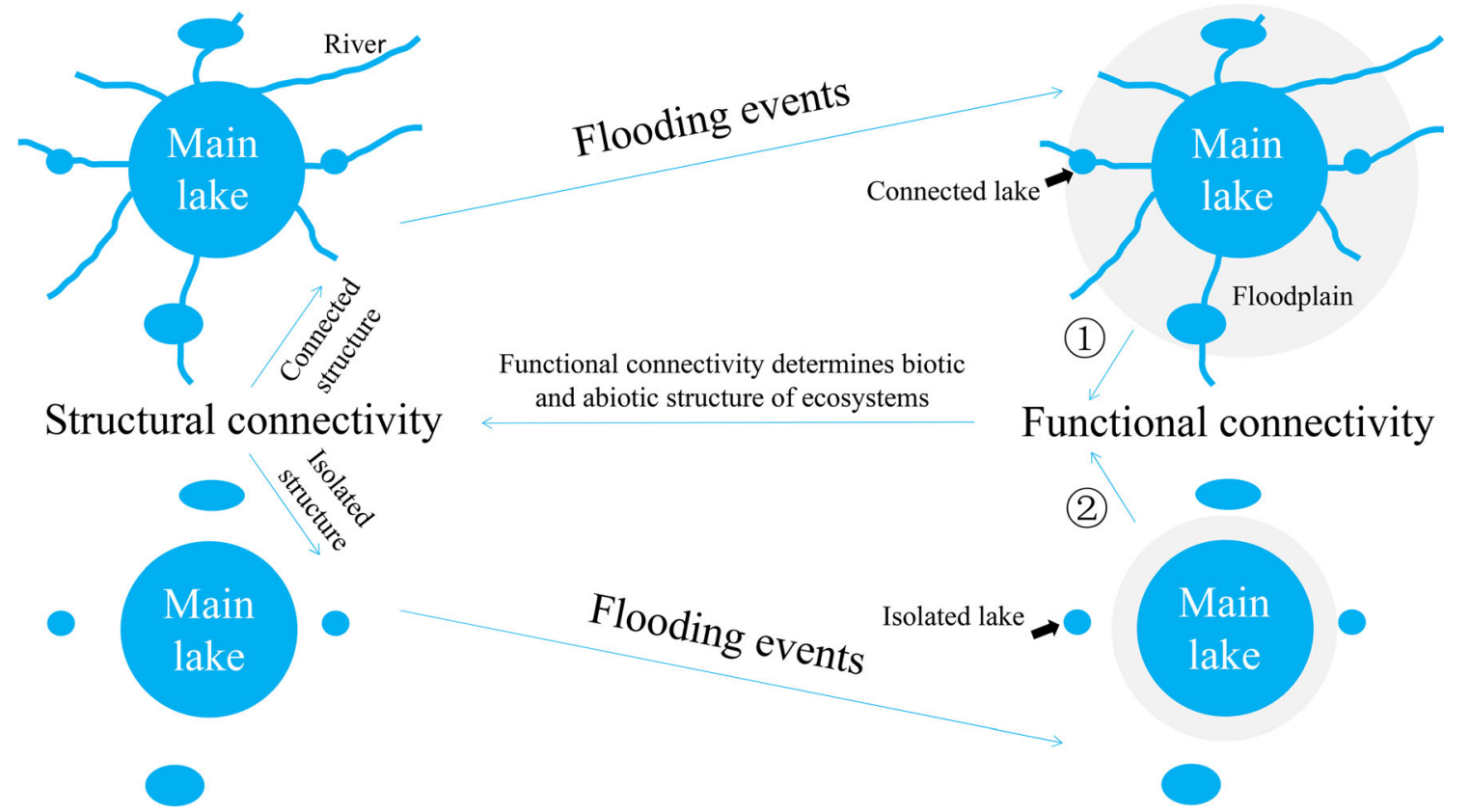

Fig. 1 The links between structural connectivity and functional connectivity (1)connected structure after flooding events determines functional connectivity; (2)isolated structure after flooding events determines functional connectivity).

hydrodynamic parameters as well as landscape patterns, which extremely impact the spatial and temporal fluctuations of hydrological processes (i.e., runoff, sediment concentration, inundation depth, and flow velocity) and ecological responses (i.e., species biodiversity and environmental homogeneity) (Tan et al. 2021). In turn, changes of those ecohydrological conditions can also dramatically influence hydrological connectivity. Considering the importance of changes in hydrological connectivity for potential ecohydrological responses should be assessed at multiscales. Hydrological connectivity at different scales can result in unpredictable environmental responses. For example, connectivity at the profile scale can influence the efficiency of water flow through soil macropores to soil depth (Zhang et al. 2018). In agricultural land use, connected macropore flow paths can increase the opportunity of pesticides and other chemicals to groundwater tables and result in groundwater pollution (Fishkis et al. 2020). Connectivity at the hillslope or catchment scale can be beneficial for assessing the health of environmental conditions (Dong et al. 2021). For example, Dong et al. (2021) concluded that reduction in hydrological connectivity is threatening the ecological integrity of freshwater ecosystems and also has negative environmental effects. Intermittent hydrological connectivity facilitates transfer of matter, energy, and organisms between habitats (Pringle 2003). In so doing, hydrological connectivity increases the possibility of organisms to colonize new habitats or exploit new resources (Reid et al. 2016). Conversely, hydrological connectivity also results in the removal of organisms or introduces competitors or predators (Reid et al. 2016). It is reasonable for assessing hydrological connectivity at microscale (i.e., profile scale) since the profile-scale assessments are very crucial to macroscales (i.e., catchment scale) (Vogel and Roth 2003; Koestel et al. 2013). However, there are some difficulties in accurately assessing hydrological connectivity to minimize its negative influences. This is because protection and management of hydrological connectivity have not been given the attentions that they deserve (Pringle 2001). There are some reasons for this. First, a range of studies have not considered the important role of hydrological connectivity in the management of fragmented landscapes. Secondly, hydrological connectivity is not fully considered until water quantity and quality problems are serious. Finally, changes in hydrological connectivity outside the boundaries of the systems could not be controlled in time by managers (Pringle 2001).

Identifying the important role of hydrological connectivity in water sources protection and management, information of hydrological connectivity should be considerably summarized (Freeman et al. 2007). Multiple literatures have highlighted the advances of hydrological connectivity in the last 40 years (Fig. 2). It is notably concluded that few studies were published on hydrological connectivity from 1980 to 2003, whereas the evolution of these studies is temporally promising since 2003. A network database constructed with information on hydrological connectivity is mostly presented on water resources $(22.9 \%)$, environmental science $(20.9 \%)$, engineering (18.4\%), and geology (18.3\%) (Fig. 2). Publications per country on hydrological connectivity indicate a wide geographical distribution, including those that characterize the USA (36.5\%). Studies in China account for $16.9 \%$ of the 


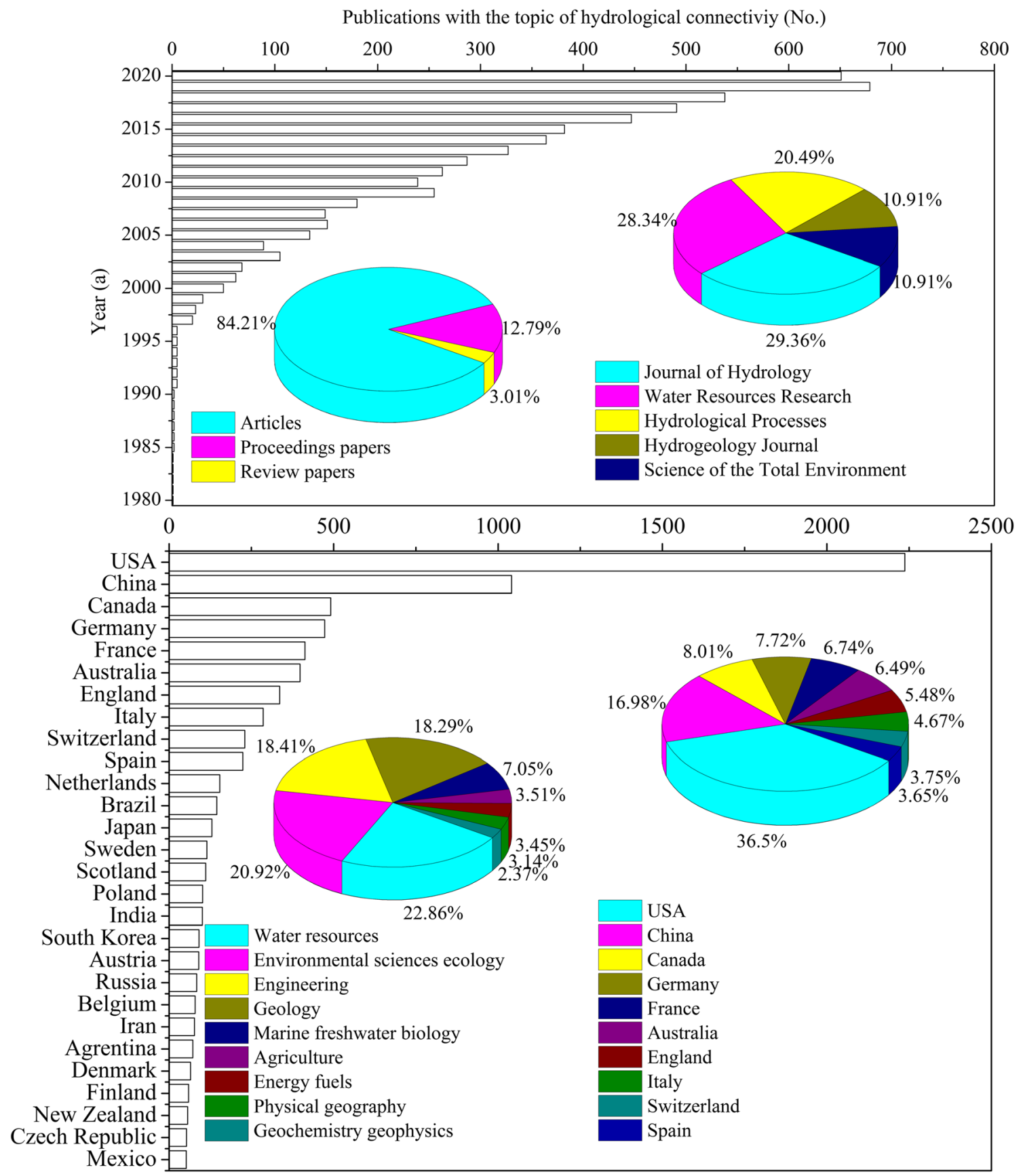

Fig. 2 The development of hydrological connectivity in the last 40 years (1980-2020).

papers and $40.0 \%$ of the papers in Europe. Although multiscale hydrological connectivity, such as macroscale (surface water connectivity, groundwater connectivity, and surface water-groundwater connectivity) and microscale (soil macropores connectivity, soil matrix connectivity, and soil macropores-matrix connectivity) connectivity has been assessed in the last 20 years (Fig. 3), they lack an integrated review, and multiple literature mainly focus on macroscale connectivity ( $95 \%$ of the papers).

In this review, in addition to an introduction on hydrological connectivity, we also attempt to address the future trends of hydrological connectivity. To address these questions, we first describe the concepts of hydrological connectivity in different environments. Secondly, we examine the different controlling factors that influence hydrological connectivity. Thirdly, we assess the approaches that determine and characterize hydrological connectivity. In the final section, hydrological connectivity at multiscales and its links with ecohydrology are concluded. We conclude with a synthesis of the current state of knowledge regarding hydrological connectivity and also provide insights on related future research trends. It is the purpose of this review to summarize 
Fig. 3 The assessment of hydrological connectivity at multiscales (A represents surface water connectivity; $\mathbf{B}$ represents groundwater connectivity; $\mathbf{C}$ represents surface watergroundwater connectivity; D represents soil macropores connectivity; $\mathbf{E}$ represents soil matrix connectivity; $\mathbf{F}$ represents soil macropores-matrix connectivity).

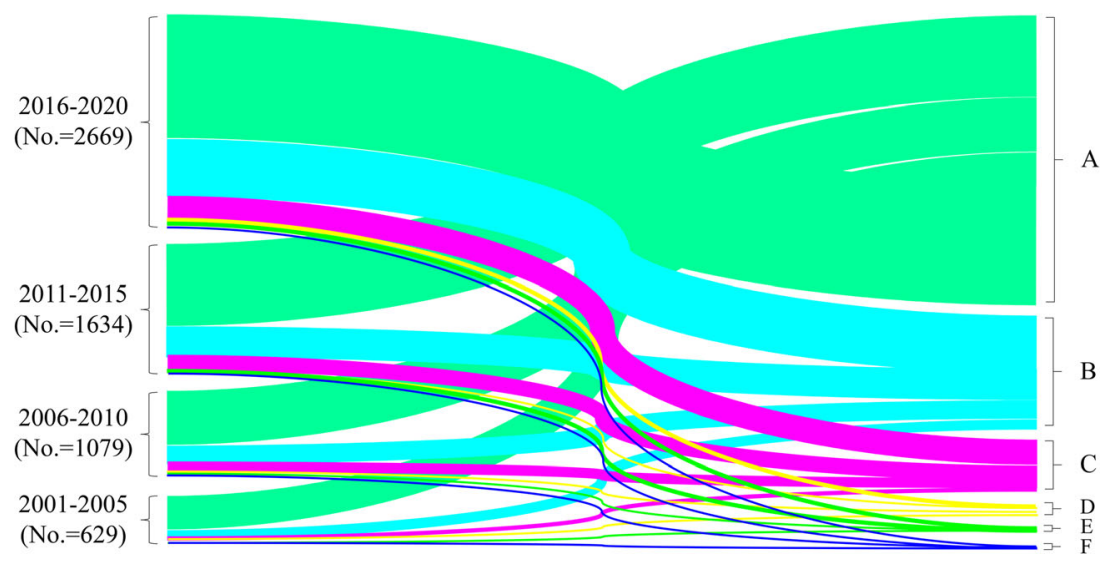

hydrological connectivity with the aim of delineating its importance on water sources management.

\section{Methods}

In the exploration of publications on hydrological connectivity, we used the Web of Science (WoS) Core Collection online systems to analyze entire papers published from 1980 to 2020 . We searched for publications related to the topic of interest, i.e., papers that focused on hydrological connectivity. For hydrological connectivity in the database, the following variables, when available, were collected: hydrological connectivity or hydrological connection or hydrologic connectivity or hydrologic connection or hydraulic connectivity or hydraulic connection. The controlling factors that affect hydrological connectivity included the following: (i) human activities (i.e., dam construction, groundwater extraction, water flow regulation and diversion, and land management) and (ii) natural factors (i.e., climate, soil characteristics, vegetation, and topography). Lastly, the approaches used to assess hydrological connectivity are concluded. The approaches included the following: (i) soil water content patterns; (ii) runoff patterns and processes; (iii) numerical models; and (iv) index of hydrological connectivity. Additionally, the number of publications per year and the number of references per country were summarized from the network database.

\section{Different concepts of hydrological connectivity in different environments}

The concept of hydrological connectivity was widely employed and originally defined by Pringle (2001). It defines the water-mediated transfer of matter, energy, and organisms within or between the elements of the hydrological cycle. Hillslope-Riparian-Stream connectivity through groundwater flow seems to be the commonly used concept of hydrological connectivity (Bracken et al. 2013). This concept is widely proposed when the timing and duration of groundwater connectivity between the rivers and the floodplain systems is the dominant influencing factor of catchment hydrology (Bracken et al. 2013). The catchment is in the locations with steep slopes. However, we still do not understand whether this concept is functional for other locations (Bracken et al. 2013).

Despite studies have assessed the concept of hydrological connectivity, there is still no consensus on how to define hydrological connectivity (Bracken et al. 2013). It is impossible to develop a standard unified concept that works in all environments. To make the concept function well in all environments, some issues should be fully considered. One issue is how it can be applicable in all environments. A range of developments have been only focused on the forested and humid temperate environments (James and Roulet 2007; Ali and Roy 2010) rather than dryland and temperate areas (Bracken and Croke 2007). Further investigations on hydrological connectivity should be paid more attentions to environments, such as dryland, colder areas, and glaciated landscapes. A second issue is how the concept works at different scales. For example, the term structural connectivity could not be as static connectivity at smaller scales. This is because surface topography can be temporally dynamic at smaller scales (Antoine et al. 2009). The spatial distributions of geomorphic units will change with spatial scales, which represent a mean of estimating the temporal scale on which hydrological connectivity should be gauged at a specific spatial scale (Bracken et al. 2015). A third issue is that we still do not understand the role of spatial and temporal heterogeneity in input precipitation and how this influences functional connectivity. The promising interest in the study of hydrological connectivity has been reflected in the discussion of the concept, with inputs coming from a wide range of disciplines (Pringle 2003). The concept of hydrological connectivity has been controversial by lack of common concerns among and within disciplines (Pringle 2003), which results in fragmented understandings of the concept in different environments. Therefore, it is unnecessary to address a standard concept of hydrological connectivity that works in all environments. We desire to develop different concepts of hydrological connectivity in different environments (Bracken et al. 2013). 


\section{Controlling factors of hydrological connectivity}

\section{Human activities}

Human activities have altered hydrological connectivity at local, regional, and even global scales (Pringle 2001). For example, Shao et al. (2020) concluded that human activities that alter hydrological connectivity at small scales can disturb the whole natural ecosystems. Human activities not only disrupt connectivity, but also enhance the improvement of connectivity. Negative human activities, such as dam construction, natural flow regimes alteration, and other physical barriers, mainly focus on fragmented landscapes in disturbing connectivity (Fig. 4) (Vivancos et al. 2021). Improvement of connectivity caused by human activities, such as canalization, removal of physical barriers, and interbasin transfers, can be targeted conservation actions (Fullerton et al. 2010).

\section{Dam construction}

Dams not only contribute to water quality and flooding events protection, but also fragment the surrounding landscape structures (Hall et al. 2011; Barbarossa et al. 2020). The fragmented changes in the landscapes will influence ecosystem itself, which will in turn disturb hydrological connectivity, such as the reduction of longitudinal connectivity (Callow and Smettem 2009). Furthermore, the changes can also affect lateral connectivity between the rivers and the floodplain systems (Barbarossa et al. 2020). By disconnecting the continuum and fragmenting the surrounding landscape structures of the rivers, dams can reduce access to feeding areas and disrupt access to spawning sites (Barbarossa et al. 2020). In addition to landscape fragmentation, dams also have threats to biodiversity of freshwater ecosystems and ultimately to the natural systems degradation (Lu et al. 2018; Barbarossa et al. 2020). Therefore, rebuilding hydrological connectivity of the damaged river systems due to enhanced dam construction can increase the biological diversity (Shao et al. 2020). Perhaps the influences of hydrological connectivity on the conservation of biological diversity will not be so immediately obvious, but in the long run, the importance of hydrological connectivity will become increasingly evident (Shao et al. 2020).

\section{Groundwater extraction}

Groundwater regimes encompass the temporal heterogeneity of the magnitude, the frequency, the duration, the timing, and the rate of changes of groundwater levels, storage, and pressures at a given spatial scale (Kath et al. 2018). Groundwater extraction can result in reduction of stream baseflow and the water storage of aquifer (Rugel et al. 2016; Kath et al. 2018), which drastically alters groundwater regimes (Kath et al.

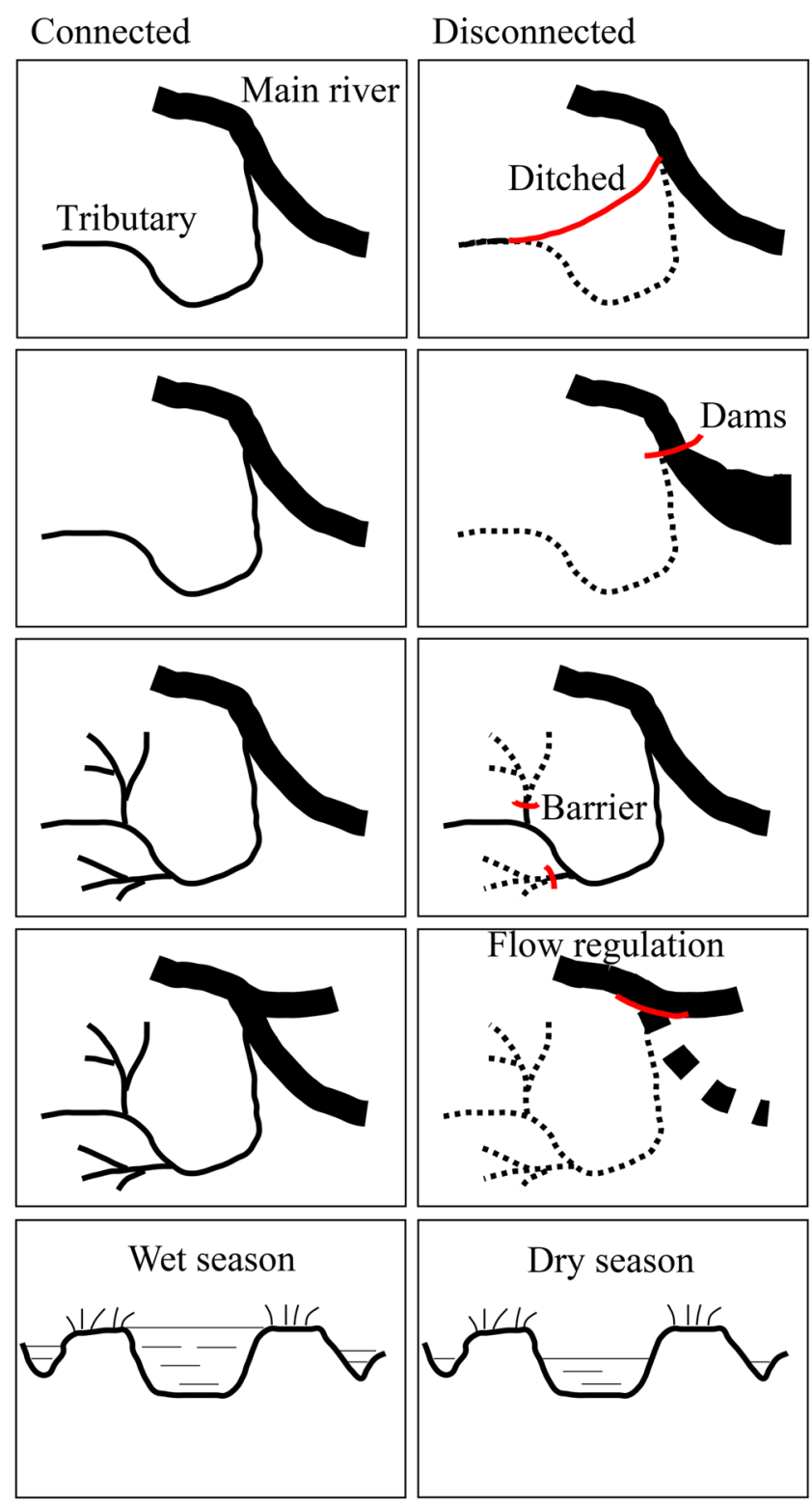

Fig. 4 The influences of partial human activities and natural factors on the degree and nature of hydrological connectivity.

2018). The changes in groundwater regimes influence hydrological connectivity between groundwater and groundwaterdepended systems (Carucci et al. 2012; Kath et al. 2018). Four mechanisms that groundwater extraction can influence connectivity are concluded. Firstly, groundwater extraction from aquifers that are connected to river networks can reduce river flows (Shentsis 2010). The decline in river flows has the potential to threaten the freshwater ecosystems, which in turn influences hydrological connectivity (Ivkovic 2009). Secondly, groundwater extraction can alter the hydraulic gradients by declining the groundwater table and altering flow directions so that a gaining river becomes a losing river, and ultimately retaining connectivity between the rivers and the surrounding landscape patches (Ivkovic 2009). Thirdly, 
groundwater extraction can increase frequency and duration of periods with reduced baseflow through groundwater discharge (Ivkovic 2009). Finally, groundwater extraction extremely influences land subsidence (Erban et al. 2014), that is, makes the groundwater table declines in many aquifers (Gleeson et al. 2010). Land subsidence caused by groundwater extraction has altered the spatial locations of landscape units and extremely influenced hydrological connectivity.

\section{Water flow regulation and diversion}

Flow regulation can be quantified by relating storage capacity to discharge. A flow regulation of $100 \%$ indicates that the entire discharge one year can be held back and released by the dam construction in the rivers. For example, the third largest discharge, the Yangtze River, is strongly affected by dams (Nilsson et al. 2005). Although dam construction may provide water for agricultural irrigation, nonreturned withdrawal from a river flow for agricultural irrigation is an additional form of flow regulation to that caused by dams water release (Nilsson et al. 2005). Flow regulation by dams disrupts the rivers natural regimes (Fig. 4). Reduction of a flood peaks reduces the frequency, the extent, and the duration of floodplain inundation. The downstream effects of flow regulation are compounded by river channelization and levee construction, which can further reduce hydrological connectivity between the rivers and the floodplain systems (Ward and Stanford 1995). Rivers can be fragmented by water diversion projects (Pringle 2003). In steep and shaded rivers where dissipation is the dominant energy flux, there is almost no temperature change due to water diversion. Water diversion increases the surface to volume ratio of the water body by decreasing the water depth (Meier et al. 2003). The construction of small scale water diversion in agricultural areas may significantly alter channel coupling in the hillslopes, which often alter hillslope hydrological connectivity (López-Vicente and Álvarez 2018).

\section{Land management}

Land management includes crop planting, changes of land use, and reservoir construction (Bracken and Croke 2007). Land management is a crucial factor in hydrological connectivity. Previous studies showed that changes of land use from forest vegetation to agricultural lands could increase the total amount of soil erosion. This is because the development of more erosive rills caused by serious soil erosion in agricultural lands could increase hydrological connectivity (Bracken and Croke 2007). Agricultural land management potentially affects flood risk management because runoff generation and subsurface drainage can be treated as paths. An important characteristic of the paths is hydrological connectivity (Posthumus et al. 2008). Changes in land management may alter hydrological connectivity. By influencing the conditions of soil structure, land management can significantly affect the local runoff generation (Posthumus et al. 2008). Land management which also causes soil crust on the soil surface or soil compaction can lead to infiltration-excess runoff (Posthumus et al. 2008). More runoff may generate and discharge more rapidly from agricultural lands, causing higher peak flow in water sources, and thus increasing hydrological connectivity (Posthumus et al. 2008). Although soil erosion on agricultural lands is generally high, the degree of hydrological connectivity is low due to the effects of agricultural terraces (Callow and Smettem 2009). However, during high precipitation or storm events, agricultural terraces could generally increase hydrological connectivity. In particular, the degree of hydrological connectivity can be enhanced when part of agricultural terraces collapse (Lesschen et al. 2009). Meerkerk et al. (2009) explored the effects of terrace on hydrological connectivity and concluded that a decrease in intact terraces could lead to an increase in hydrological connectivity in agricultural catchments.

\section{Natural factors}

\section{Climate}

Precipitation is one of the most crucial events of climate. The interaction between precipitation and hydrological connectivity is dynamic (Bracken and Croke 2007). This is because the input of precipitation is always spatially and temporally changing. Precipitation intensity and duration are important drivers that influence connected flow within a catchment (Bracken and Croke 2007; Masselink et al. 2017). In the initial stage of precipitation, a low-intensity precipitation can wet up and further saturate soil surfaces. The runoff generation is promoted when a high-intensity pulse occurs, which results in high connected flow. The microscale soil surface roughness changes and soil crusts develop as soil aggregates are broken down when the soils become saturated during the precipitation events (Bracken and Croke 2007). However, in dry soil surfaces, a high-intensity pulse will not affect connected flow. The temporal patterns of high-intensity precipitation events are also factors controlling hydrological connectivity at the hillslope and catchment scales (Bracken and Croke 2007).

Although climate change analysis is common in the literature, few studies have looked at the influences of climate change on hydrological connectivity (Kompanizare et al. 2018). Climate change could increase or decrease hydrological connectivity (Karim et al. 2016). Some studies concluded that climate change has a greater influence on the duration of hydrological connectivity than on its spatial distribution (Kompanizare et al. 2018). For example, the average duration of hydrological connectivity increased under a wetter climate, whereas the average duration decreased under a drier climate 
(Karim et al. 2016). The increase in precipitation under a wetter climate and decrease in precipitation under a drier climate could result in larger changes of hydrological connectivity than the impacts of dam construction on hydrological connectivity (Karim et al. 2015). Meanwhile, we cannot neglect the frequent occur of extreme events, such as storm events, and its interaction with hydrological connectivity (Bracken and Croke 2007). Storm intensity and duration are important to producing hydrological connectivity. Other storm characteristics, such as the temporal heterogeneity in precipitation throughout the storm events and the spatial heterogeneity in precipitation within the catchment, also influence hydrological connectivity (Bracken and Croke 2007).

\section{Soil characteristics}

Soil water content is one of the most considering elements of soil characteristics, which significantly influencing hydrological connectivity. Studies showed that there was a great difference in hydrological connectivity between dry and wet soil conditions (Molina et al. 2009). As antecedent soil water content increases, the likelihood of connections between sources of runoff generation increases (Bracken and Croke 2007). This is because saturated layers are extensive where wetter soil conditions prevail, providing a high degree of hydrological connectivity between the hillslope connected flow paths (Tetzlaff et al. 2007). Antecedent soil water content has a larger impact on the spatial patterns of hydrological connectivity (Bracken and Croke 2007), and in turn higher hydrological connectivity can also lead to a higher soil water content (Xie et al. 2021). Another important factor of soil characteristics is soil surface roughness (Bracken and Croke 2007). Hydrological connectivity influenced by soil surface roughness is controlled by slope. Soil surfaces with smooth areas are not extremely affected by gradient, but for soil surfaces with rough areas, gradient can affect depression storage, runoff generation, and the development of rills (Bracken and Croke 2007). As the rills develop increasingly, preferential flow paths on the soil surface also develop (Zhang et al. 2018), and water flow concentrate within those connected flow paths, thus increasing hydrological connectivity (Bracken and Croke 2007). Furthermore, soil infiltration is a key and complex process in runoff generation and hydrological connectivity. The spatial heterogeneity of soil infiltration is more crucial for hillslope and catchment connectivity. As runoff generation is produced, a key factor for hydrological connectivity is whether runoff can continue on the hillslope soil surface or produce connected flow. In terms of hydrological connectivity, a sufficient volume of water is needed to produce connected flow (Bracken and Croke 2007).

\section{Vegetation}

Vegetation is one of the main factors influencing hydrological connectivity at all scales (Bracken and Croke 2007). Vegetation can influence water inputs and runoff through interception, formation of leaf litter, and transpiration and thus reduce rain-splash and soil crust formation (Fig. 5). During high-intensity precipitation events, runoff generation occurs on the bare land areas, but runoff infiltrates into the soils when it reaches a vegetated land areas, and in turn limiting hydrological connectivity (Bracken and Croke 2007). The spatial changes of vegetation patterns caused by overgrazing, the reforestation, or afforestation have given rise to the modifications of hydrological connectivity within the catchments (Lesschen et al. 2009; Molina et al. 2009). The vegetation spatial patterns appear to be more important than the disappearance of the agricultural terraces and channels to imply the changes in hydrological connectivity at the catchment scales (López-Vicente et al. 2013). There has been a lot of research based on spatial heterogeneity in vegetation and how this is related to hydrological connectivity. Cerdà (1997) showed that vegetation recovery could reduce water transfer to the main connected flow paths. Banks et al. (2011) concluded that vegetation can affect the state of connection between surface water and groundwater and also create a disconnection in some instances (Fig. 5). Mayor et al. (2019) stated that hydrological connectivity nonlinearly increased with decreasing vegetation cover.

\section{Topography}

Topography has a complex effect on hydrological connectivity. This is because the effects of topography on hydrological connectivity are subject to change (Bracken and Croke 2007). The amplitude and spatial organization of topography in the field play a crucial role in connecting or disconnecting one area with another within the catchment (Appels et al. 2016). Slope length is an important factor influencing hydrological connectivity at the hillslope and catchment scales, but it is relatively not important at the plot scales (Bracken and Croke 2007). On longer slopes, the slope will reduce runoff generation because runoff could not reach the slope base. Runoff generation decreased with increasing slope length due to infiltration (Bracken and Croke 2007). However, on some longer slopes with low infiltration, the runoff generation increases. The slope length is complicated by the development of rills. Rills could increase infiltration when soil crusts are broken. But the development of rills could also increase runoff generation because they can be treated as connected preferential flow paths on the soil surface (Bracken and Croke 2007; Zhang et al. 2018). Slope gradient is also a structural connectivity factor. On steeper slopes with the same amount of precipitation, there is a greater reduction in the infiltration 
Fig. 5 The effects of vegetation on the degree of hydrological connectivity in the soil-plantatmosphere-continuum systems (A represents well connected, B represents poorly connected. White $=$ ridges, black $=$ channels $)$ (Good et al. 2015; Larsen et al. 2017).

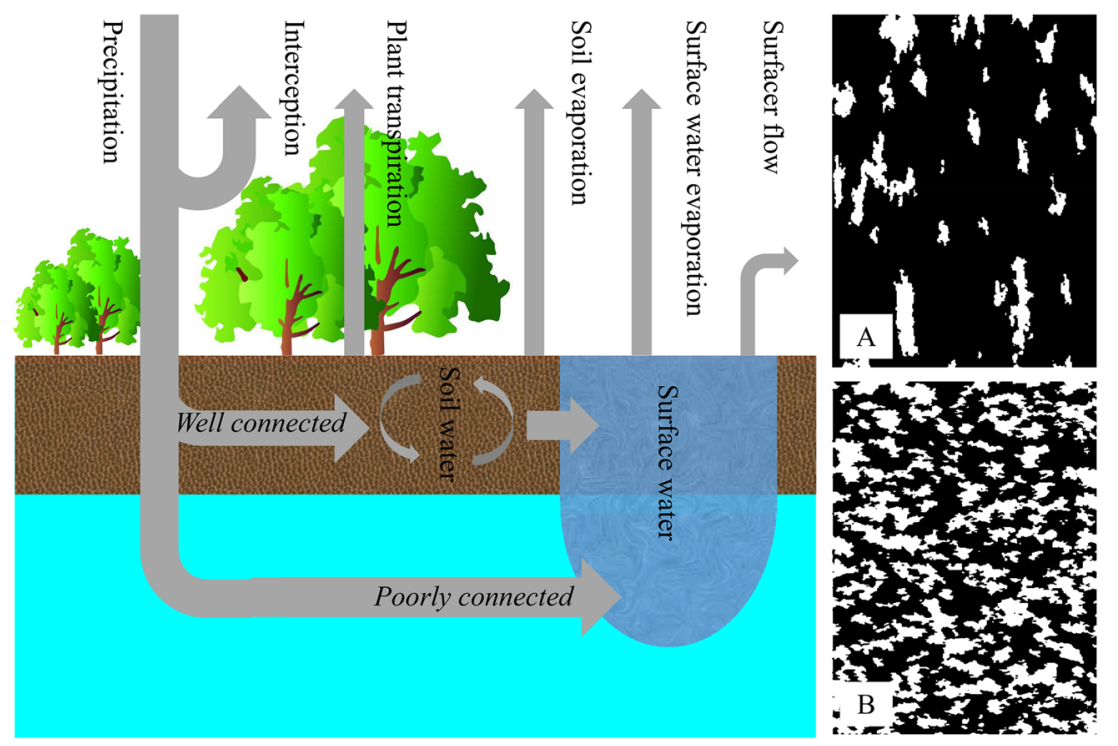

capacity due to the shallow soil depth. Slope gradient affects the amount of energy available for surface flow, increasing the surface flow velocity and influencing the functional connectivity (Reaney et al. 2014).

Topography depressions increase the complexity of hydrological connectivity (Wang et al. 2021b). Topography depressions are disconnected in most conditions, and the connectivity between those depressions will occur only when there is sufficient precipitation (Wang et al. 2021b). In reality, the spatial patterns of depressions and the real hydrological processes in depression dominated areas could not be estimated accurately. Some studies have assessed the changes of hydrological connectivity in those areas (Chu et al. 2013; Wang et al. 2021b). Those studies concluded that depressions could block hydrological processes and thus retain hydrological connectivity. Other topography characteristics, such as road networks and tracks, are the significant components of hydrological connectivity within the catchment (Tague and Band 2001). Hydrological connectivity caused by roads and tracks leads to the development of how best to manage catchment hydrological processes.

\section{Approaches to investigating hydrological connectivity}

\section{Soil water content patterns}

This approach is on the basis of the promise that soil water content patterns can well reflect how water moves through the catchment during storm events. In particular, soil water content patterns can distinguish the facts of how water produces hydrological connectivity (Bracken et al. 2013). The approach is also focused on the spatial patterns of soil water content at the hillslope scales. Previous studies concluded that hydrologically connected features facilitated by spatial patterns of soil water content can form more concentrated flow paths which might decrease the travel times of materials migrated by water (Western et al. 2001; Knudby and Carrera 2005). Once drysoil barriers become wetter, hydrological connectivity is established, lateral flow can occur, and soil water can be directly connected with the downslope water (Mcnamara et al. 2005). In a dry state, hillslopes are hydrologically disconnected, and the dominant flow direction is vertical. Spatial patterns of soil water content are unorganized because there is no topographic control on the patterns (Grayson et al. 1997). In a wet state, hillslopes are connected through lateral flow. Spatial patterns of soil water content are spatially organized because topographic controls are primary factors on soil water content distribution (Grayson et al. 1997; Stieglitz et al. 2003; Mcnamara et al. 2005).

\section{Runoff patterns and processes}

Hydrological connectivity with runoff processes is a critical concept for understanding catchment hydrological responses (Saffarpour et al. 2016). Hydrological connectivity determines how precipitation is transformed into runoff and how this runoff moves from the hillslopes into the surface water sources (Cammeraat 2002; Reaney et al. 2014). The spatial heterogeneity of runoff patterns on the hillslopes and the subsequent development of runoff processes paths can indicate the changes in runoff connectivity. Connectivity of runoff networks may exhibit threshold behavior. This is because initiation of runoff generation requires a certain level of precipitation infiltration (Gomi et al. 2008). Approaches characterizing runoff patterns and processes to explore hydrological connectivity bridges a range of concepts of hydrological 
connectivity at all scales (Bracken et al. 2013). Field studies have explored how hydrological connectivity developed through runoff processes (Smith et al. 2010). For example, Reaney et al. (2014), by means of the Connectivity of Runoff Model, concluded that slope length, slope gradient, and soil infiltration are the three main factors in determining runoff connectivity. They stated that the time required for runoff generation to reach an efficient flow channel can determine the degree of hydrological connectivity and also reflect the approaching of hydrological connectivity (Reaney et al. 2014). In reality, hydrological connectivity typically increases because runoff processes can develop with less precipitation and over smaller drainage time (Wilson et al. 2021).

\section{Numerical models}

The earliest numerical models did not fully consider hydrological connectivity, but they estimated the continuity of runoff generation paths (Bracken et al. 2013). Few models have treated hydrological connectivity as an emergent parameter to estimate the changes of flow connectivity (Bracken et al. 2013). Recently, promising numerical models considering hydrological connectivity have been improved to explore factors, such as topographic characteristics, soil characteristics, and vegetation conditions, affecting flow connections (Callow and Smettem 2009; Meerkerk et al. 2009). Lesschen et al. (2009) developed a LAPSUS model considering vegetation patches and agricultural terraces to imply their effects on hydrological connectivity at the catchment scales. Birkel et al. (2010) improved a catchment precipitation-runoff model, which fully considered the dynamic characteristics of hydrological processes in the saturated zones. They concluded that the changes of the saturated zones can better reflect the changes in hydrological connectivity. Three categories numerical modeling hydrological connectivity are (i) watershed models, (ii) groundwater model, and (iii) coupling surface water-groundwater models (Markstrom et al. 2008). Coupling surface water-groundwater model should be the best suitable model which can better assess hydrological connectivity in the systems where multiple flow regimes are dominant (Markstrom et al. 2008). To improve the accuracy of the above three numerical models, some empirical methodologies should be fully considered in further studies. These methodologies, such as statistical model, mass balance and solute tracers methods, and remote sensing and emerging geophysical techniques, could do more contributions to the numerical models parameterization when we estimate hydrological connectivity in different systems (Golden et al. 2014).

\section{Index of hydrological connectivity}

The index of hydrological connectivity proposed by Borselli et al. (2008) has been applied in different environments and has also been adjusted at specific study areas. Index of hydrological connectivity is selected for three reasons: (i) it is a primarily common used index; (ii) it can be easily characterized by GIS; and (iii) it can be used for assessing changes in hydrological connectivity with human activities and natural factors (López-Vicente and Álvarez 2018). Sougnez et al. (2011) indicated the effects of the spatial patterns of vegetation distribution on the index of hydrological connectivity. López-Vicente et al. (2013) assessed the influences of changes of land use on changes of the index of hydrological connectivity. The index of hydrological connectivity has also been applied to identify the extent of pollutants. Ortíz-Rodríguez et al. (2017) characterized the spatial distributions of the index of hydrological connectivity in active volcanic areas. Sun et al. (2021) used the index of hydrological connectivity to assess the effects of ditch construction on solute transport paths, and they concluded that ditch construction could make the paths shorter and more fragmented, which could reduce the index of hydrological connectivity in agricultural catchment.

\section{Hydrological connectivity at multiscales and its effects on ecohydrology}

\section{Hydrological connectivity at macroscales}

\section{Hillslope-river/stream/lake connectivity}

Hillslope-river/stream/lake connectivity defines the volume and speed of runoff entering surface water sources through natural seepage and artificial drainage systems (Zuecco et al. 2019). This connectivity directly promotes the interaction of terrestrial systems with aquatic systems (Covino 2017). Hillslope-river/stream/lake connectivity both at the surface and in the subsurface should be fully considered (Fig. 6) (Blume and Meerveld 2015). Surface connectivity is often discussed for surface runoff and sediment transport, whereas subsurface connectivity is more difficult to quantify (Blume and Meerveld 2015). Surface connectivity is relatively sporadic and can occur when precipitation and saturation conditions are sufficient for water to spill out of midslope surface depressions and across the riparian zones into the surface water sources (Blume and Meerveld 2015; Hueso-González et al. 2015; Chiasson-Poirier et al. 2020). Subsurface connectivity occurs when the hillslopes are hydrologically connected to the surface water sources by subsurface flow (Blume and Meerveld 2015). Subsurface flow is promoted after the development of saturation above a less permeable layer and subsequent lateral subsurface flow through the saturated layers (Blume and Meerveld 2015; Chiasson-Poirier et al. 2020). Subsurface flow can also occur when groundwater table increasingly reach more permeable layers and lateral flow occur 


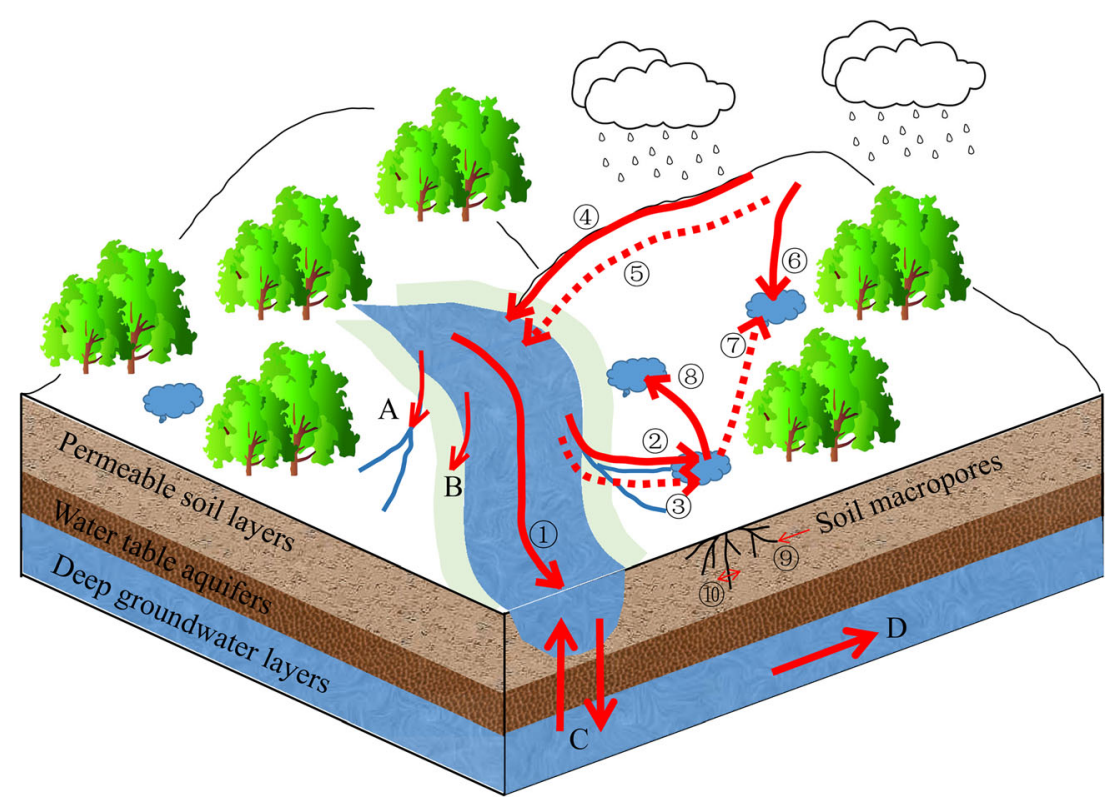

Fig. 6 The form of hydrological connectivity in natural ecosystems (1) longitudinal connectivity in rivers; (2)river-lake connectivity through surface water flow; (3)river-lake connectivity through subsurface water flow; (4)hillslope-river connectivity through surface runoff; (5)hillsloperiver connectivity through shallow subsurface water flow; (6) hillslopelake connectivity through surface runoff; (7)Lake-lake connectivity

along the more permeable layers (Blume and Meerveld 2015). Some studies found that the size of the upslope accumulated areas on the hillslopes could also control the duration of subsurface connectivity (Jencso et al. 2010). It is difficult to assess surface or subsurface connectivity accurately. This is because surface or subsurface water must pass through the riparian zones prior to connecting to surface aquatic systems (Chiasson-Poirier et al. 2020). A smaller part of hillslopes can be hydrologically connected to the surface water sources only during certain storm or snowmelt events, whereas other hillslopes may remain hydrologically disconnected (Mcguire and Mcdonnell 2010; Von Freyberg et al. 2014; Blume and Meerveld 2015; Brannen et al. 2015). In wetter conditions during storm or snowmelt events, areas on the hillslopes are hydrologically connected via lateral subsurface flow (Grayson et al. 1997; Stieglitz et al. 2003). However, in drier conditions, areas on the hillslopes are not hydrologically connected (Grayson et al. 1997; James and Roulet 2007). Therefore, such conditions can extremely influence the duration of the connectivity. In general, some hillslopes can be hydrologically connected to the surface water sources for several months per year or for a whole year, whereas others for only several hours or days or not connected at all (Mcguire and Mcdonnell 2010; Blume and Meerveld 2015).

Understanding hillslope-river/stream/lake connectivity can help to assess implications of land management on the surface water sources quantity and quality (Pringle 2003; Covino 2017). In mountainous areas, the hillslopes are often agricultural land uses, such as terraces. Fertilizers and pesticides are through subsurface water flow; 8) lake-lake connectivity through surface water flow; (9)soil macropores connectivity; (10)soil macroporesmatrix connectivity; A river-stream connectivity; B river-floodplain wetland connectivity; $\mathbf{C}$ surface water-groundwater connectivity; $\mathbf{D}$ groundwater connectivity).

often applied to the areas (Von Freyberg et al. 2014). The connectivity is linked to the transport of those pollutants from the hillslopes to the surface aquatic systems. In particular under storm events, surface runoff can carry lots of pollutants to the downstream. Pollutants carried by surface runoff reaching the surface water sources lead to the contamination and eutrophication of aquatic systems (Appels et al. 2011). Therefore, land managers should make accurate plans for the hillslopes. For example, in future hillslope management, runoffgenerating areas on the hillslopes of agricultural lands must not be spatially connected to the surface water sources to prevent the aquatic systems deterioration (Smith et al. 2010).

\section{River-floodplain wetland connectivity}

Floodplain wetlands are complex systems hydrologically connected to the rivers (Fig. 6) (Addy and Wilkinson 2021). By sustaining surface water and groundwater storage, floodplain wetlands can provide floodwater storage and can also contribute up to $50 \%$ of the river flow in upland catchments (Addy and Wilkinson 2021). Precipitation is an important source of water supply to floodplain wetlands. In addition to precipitation, change in river flow during high flow periods is another important factor that drives connections between the rivers and the floodplain wetlands (Chen et al. 2020). The connectivity promotes the fast-moving water from the rivers to the floodplain wetlands, and water can later return to the river systems (Chen et al. 2020). The degree of river-floodplain wetland connectivity generally results from different water 
levels (Chen et al. 2020). For example, the degree of the connectivity can be treated as disconnectivity when the river water level is lower than that within floodplain wetlands (Chen et al. 2020). As water level increases, the rivers and the floodplain wetlands are hydrologically connected (Dong et al. 2021). Meanwhile, the degree of the connectivity is also controlled by the declining trend in the precipitation and the increase in the temperature, which result in the deterioration of the connectivity (Cui et al. 2021). Furthermore, human activities, such as dam construction and farmland irrigation projects, not only fragment the spatial distribution patterns of rivers, but also decrease the connectivity (Cui et al. 2021).

River-floodplain wetland connectivity is crucial to hydrological and biogeochemical processes in river corridors (Addy and Wilkinson 2021). Although permanent surface water sources are present in rivers, this does not imply that the floodplain wetlands are not at risk of species biodiversity and productivity reduction and also the decline of river-floodplain wetland connectivity (Xia et al. 2016; Cui et al. 2021). The biodiversity of floodplain wetlands mainly depends on the distance between the rivers and the floodplain wetlands, and also on the area and structure of the floodplain wetlands. Dong et al. (2021) found that the increase in connectivity causes low spatial environmental heterogeneity and biotic homogenization of floodplain wetlands landscapes. Some studies concluded that floodplain wetlands are faced with degradation in drier seasons, causing reduction in riverfloodplain connectivity (Liu et al. 2020). In drier climate, water quality of floodplain wetlands is worse than that in flooding events (Liu et al. 2020). This is because surface water level in dry seasons is lower than the median main river stage, which results in the disconnectivity between the rivers and the floodplain wetlands. The mass exchange, such as nutrients transport, from floodplain wetlands to other surface water sources is extremely impeded (Liu et al. 2020). Therefore, to sustain the ecological services of the floodplain wetlands, it is crucial to understand how the extent, timing, and duration of hydrological connectivity to the rivers vary with climate changes (Karim et al. 2016).

\section{River-river/stream/lake connectivity}

Although rivers/streams/lakes are only a part of surface water sources on the earth, they are more accessible to people (Pekel et al. 2016). It is extremely challenging to predict seasonal dynamics of those surface water (Tesemma et al. 2015; Pekel et al. 2016). To better quantify those surface water responses to precipitation and snowmelt events, it is particularly important to understand how, when, and where connectivity between those surface water occurs (Trigg et al. 2013; Zuecco et al. 2019). River-river/stream/lake connectivity can promote mass exchange between the two different surface water sources and also the renewal of water sources in each aquatic systems (Fig. 6) (Von Freyberg et al. 2014).
River connectivity has been a widespread focus in the protection of river ecosystems. Understanding the importance of river connectivity helps assess some river flow processes, such as the river response to the obstacles, the functions of river corridors, and the retention of rivers (Hu et al. 2019a). For example, dam construction on the main trunks has a larger influence on river connectivity than that on the tributaries (Shao et al. 2020). Disturbance of the connectivity at smaller scales impedes the movement of aquatic organisms even the whole river systems (Shao et al. 2020). Longitudinal connectivity implies the unobstructed transport of nutrients in rivers. The connectivity helps the unobstructed river flow along the longitudinal axis (Shao et al. 2019). High longitudinal connectivity of rivers includes two conditions: (1) continuous water flow and a strong ability of materials transfer between upstream and downstream and (2) connected flow paths that can ensure water flow passing. Longitudinal connectivity is a common index in river health assessment. In recent decades, longitudinal connectivity has been developed (Deng et al. 2018). Longitudinal connectivity is essential for the survival of species, ensuring the transport of nutrients, and the migration of aquatic organisms (Wang et al. 2021a). Hydropower station construction can reduce river flow, block migration routes, and lead to reduction of species (Wang et al. 2021a). Streams near large rivers tend to support species healthy than streams that lack connections with the rivers (Hitt and Angermeier 2008). River-stream connectivity can affect fish assemblage structure. The effects of river-stream connectivity will diminish as the distance between the main rivers and the stream sites increases (Hitt and Angermeier 2008).

Lakes are periodically connected to the rivers during high water periods, but the frequency, the duration, and the timing of the connections vary with the elevation of the riverbanks or the elevation of a channel that often joints the lake to the river (Miranda 2005; Zhang et al. 2020). More species are recorded in lakes that connect to the rivers than in lakes that intermittently connected to the rivers (Miranda 2005). Lake size, depth, distance from the river, and age affect the connections between the lakes and the rivers. After lakes separate from the rivers, they will trap sediments from annual flooding events and become shallower over years. Lakes that are hydrologically connected to the rivers tend to be deeper and cleaner, whereas those disconnected lakes tend to be shallower and turbid (Miranda 2005). A prolonged drought period can lead to the isolation of lateral lakes connected to the main rivers. This isolation processes can cause lake segmentation into some small isolated water bodies during the drought period. Meanwhile, the eutrophication in the isolated water bodies can generally occur. After the connection between the rivers and the lakes was reestablished, some changes in the characteristics of each lake environments occur (Casanova et al. 2009). River connected lakes exhibit a high degree of biodiversity, leading to an enhanced biological diversity of aquatic ecosystems (Chi et al. 2016). 


\section{Lake-lake connectivity}

Shallow lakes have two alternative stable states: a clear water state with low fish densities at low nutrients loads and a turbid water state with high fish densities at high nutrients loads (Van de Meutter et al. 2006). Fish densities are extremely reduced by lake drainage. Fish can migrate from lake to lake through the lake connections (Van de Meutter et al. 2006). Geographically isolated lakes can be hydrologically connected (Ameli and Creed 2017). Hydrological connectivity between these isolated lakes can be visualized through multiple paths, such as surface runoff, groundwater, and perched groundwater discharge (Golden et al. 2014; Ameli and Creed 2017). The degree of the connectivity between isolated lakes and the main lake can be assessed (Fig. 6). In drought conditions, the duration of the connectivity between the main lake and seasonal isolated lower-lying lakes is much longer than those between the main lake and upper-lying lakes because of different inundation times (Tan et al. 2019). However, in floods conditions, there are minor differences in the duration of the connectivity between the main lake and those seasonal isolated lakes. Those seasonal isolated lakes have short hydroperiods and shallow water depth. Lowerlying isolated lakes tend to be connected earlier and disconnected later to the main lake than upper-lying isolated lakes (Tan et al. 2019). As water level recesses in lakes, and lakelake connectivity is declined, the ecosystem size is small, which results in reduction in species turnover. In addition, the shrinkage of ecosystem size can change the structure of food web (Fig. 7) (Dong et al. 2021).

\section{River/stream/lake-groundwater connectivity}

Surface water-groundwater systems are generally classified as connected or disconnected systems (Fig. 6) (Banks et al. 2011; Addy and Wilkinson 2021). Connected systems are either gaining system (i.e., groundwater to river flow) or losing system (river flow to groundwater) (Banks et al. 2011). Studies of gaining system are fully considered instead of focusing on a losing system (Martinez et al. 2015). For example, when groundwater levels drop to be lower than surface water level, the river transforms from a gaining status to a losing status, which promotes surface water sources infiltration into the riparian zones groundwater (Huang et al. 2021). Disconnected systems show that changes in water level cannot significantly affect infiltration rates from the rivers when flow losses through the unsaturated zones (Banks et al. 2011). Disconnected systems tend to be completely disconnected or be in transitional states (Li et al. 2017). Completely disconnected systems reflect that changes in the water table could not affect infiltration rate from surface water bodies to the aquifer, whereas disconnected systems in transitional states indicate that changes in the water table may affect infiltration rate. The term disconnection may incorrectly indicate no flow between surface water and groundwater. It is still unclear about under what conditions surface water will become disconnected from groundwater (Brunner et al. 2009). Further lowering of groundwater table within disconnected systems will not significantly increase the infiltration rate of the surface water (Brunner et al. 2009). Despite the theoretical criteria for disconnectivity is easily defined in a losing system, assessing spatial and temporal disconnectivity between surface water and groundwater in the field is difficult (Banks et al. 2011).

Surface water-groundwater connectivity can be assessed by direct measurements, heat tracers, and environmental isotopes (Huang et al. 2021). This connectivity is controlled by three factors: (1) the position of the river channels within the landscape and the morphology of the catchments; (2) the hydraulic conductivity of the river bed and the alluvial deposits; and (3) the relation of the stream elevation to the water level of
Fig. 7 The links between hydrological connectivity and water quantity and quality and its influences on healthy of an aquatic ecosystem.

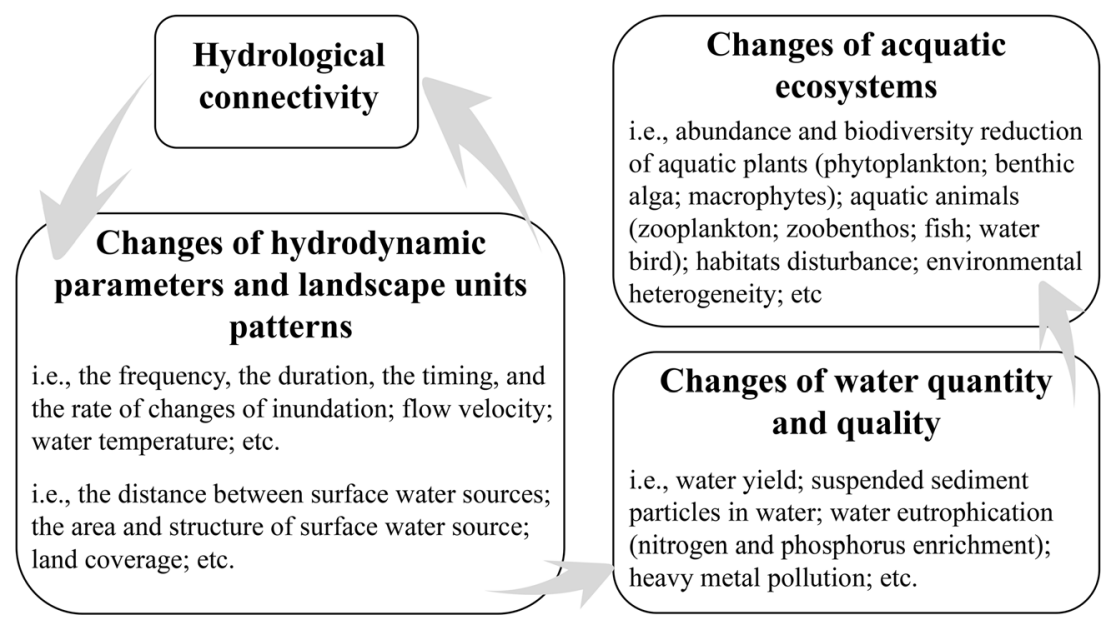


the adjacent aquifers (Dor et al. 2011; Martinez et al. 2015; Lapworth et al. 2021). Surface water-groundwater connectivity is performed when the saturated zones are distributed into the transmissive zones (Brannen et al. 2015). The connectivity also occurs when there is a continuous hydraulic gradient (Brannen et al. 2015; Chen et al. 2020). For water sources management, it is crucial to determine whether surface water-groundwater connectivity is present or not, and in what manner the connectivity exists (Li et al. 2017). For example, on China Loess Plateau with thick loess layer, a deep unsaturated zone, a low precipitation, and a dried soil layer, we assume that groundwater contributes little to surface water sources. However, strong surface water-groundwater connectivity occurs in the thick loess layers ( $\mathrm{Li}$ et al. 2017). Understanding the links between the two water systems is beneficial for how to distinguish connected or disconnected flow paths where substances can migrate and transfer within the aquatic systems (Martinez et al. 2015). Such can encourage managers to do more endeavors for water purification. In many cases, the connectivity accelerates the dissolved substances removal from surface water sources because shallow aquatic sediments are a sink of many substances (i.e., heavy metal) (Sawyer et al. 2015). Conversely, the connectivity can also deteriorate surface water quality when the groundwater systems are the contaminants source (Sawyer et al. 2015).

\section{Groundwater connectivity}

Groundwater flow which belongs to subsurface aquifers is also a key component of water sources (Rassam et al. 2013). Groundwater flow plays an important role in ecosystem services, food security, and water quantity and quality (Gleeson et al. 2016). The overexploitation of groundwater sources has led to the depletion of groundwater table and the deterioration of groundwater quality in arid and semi-arid regions. When some areas where the groundwater table is near the soil surface and the hydraulic gradient is conducive during wet seasons, groundwater connectivity should be considered (Fig. 6) (Brannen et al. 2015). Groundwater connectivity differs significantly from connectivity between different surface water sources in terms of its timing and length (Ameli and Creed 2017). Groundwater connectivity is controlled by the heterogeneity of aquifer properties (Collins et al. 2020). Groundwater connectivity has an important control on soil carbon combustion (Hokanson et al. 2016) and controls the sustainability of abstraction and the transport of solutes at a catchment scale (Collins et al. 2020). Even small groundwater connectivity can be critical for delivering solutes (Neff and Rosenberry 2018). Knowledge of groundwater connectivity can be crucial for groundwater sources protection and management.

\section{Hydrological connectivity at microscales}

\section{Soil macropores connectivity}

Soil macropores formed by dead root channels, soil fauna, cracks, fissures, and natural soil pipes as continuous openings occur commonly in soils (Beven and Germann 1982, 2013; Zhang et al. 2015; Zhang et al. 2016a, 2016b, 2018; Nimmo 2021 ). It is typically considered that $70-85 \%$ water flow occurs through localized soil macropores quickly bypassing the soil matrix (Hendrickx and Flury 2001). However, not all soil macropores contribute to water flow (Larsbo et al. 2014; Katuwal et al. 2015; Naveed et al. 2016). Studies have shown that $30 \%$ of soil macropores benefit for water flow (Sammartino et al. 2012). Large soil macropores that are disconnected from the rest of soil pores space cannot allow any water flow at all (Fig. 8). Water flows through soil macropores; in fact, we regard the phenomena as soil macropore flow (Yu et al. 2020). In general, soil macropore flow is mainly influenced by the size and number of soil macropores, the hydrophobic organic coatings of soil macropores boundaries, the amount of surface water supply, and the temperature of infiltrating water (Watanabe and Kugisaki 2017; Beven 2018). In the case of soil macropore flow which is connected to surface water supply, water flow might occur rapidly to soil depth for generating fast subsurface responses (Beven 2018). However, many soil macropores may not be connected to a surface water supply and may not be active except when soil becomes saturated (Beven 2018).

Soil macropores, i.e., connected macropores and isolated macropores, in soils can form a complex network. Interconnected soil macropores can improve soil aeration and strongly affect water flow and chemical transport and reaction process (Hussain et al. 2019; Pittman et al. 2020). Those well connected, functional, and hydrologically active soil macropores with high connectivity are worthy to positively increase water infiltration (Jarvis et al. 2017; Zhang et al. 2018; Borges et al. 2019; Ma et al. 2021). High soil macropores connectivity indicates the presence of connected soil macropores which defines no greater resistance to water flow, but isolated soil macropores can offer disconnected flow paths (Borges et al. 2019). In general, more connected soil macropores probably contribute to the smooth of water flow (Rezanezhad et al. 2009). High soil macropores connectivity is possibly caused by good soil structures and well established biological activity (Wu et al. 2017; Soracco et al. 2019). Root channels can contribute more to the high soil macropores connectivity (Hu et al. 2019b). More connected soil macropores can be closely correlated with rich root systems (Zhang et al. 2015). Root systems have created more powerful flow paths which may connect with these existing soil macropores to make them hydrologically active (Hu et al. 2019b). Besides root systems, the connectivity is also more related with soil 


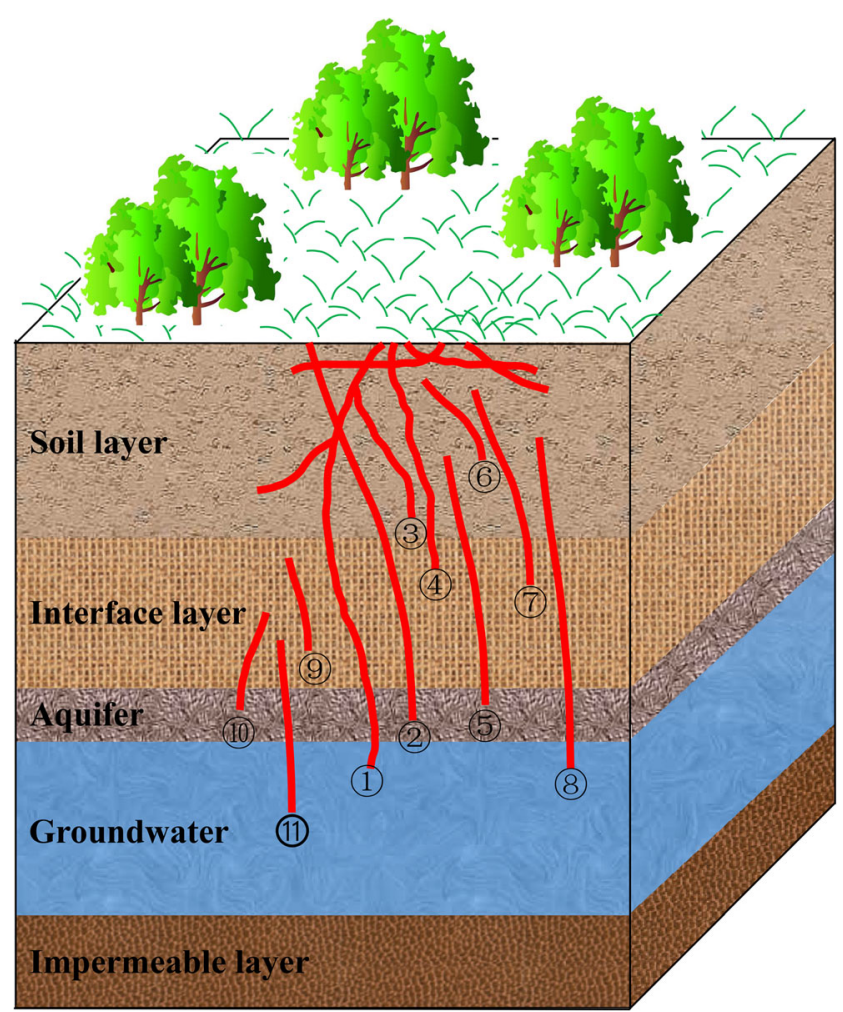

Fig. 8 The forms of soil macropores distributed in soils (1) soil macropores connected to the surface water supply reach groundwater; (2) soil macropores connected to the surface water supply reach aquifer; (3) soil macropores connected to the surface water supply reach surface soil layer; (4)soil macropores connected to the surface water supply reach interface layer; (5)soil macropores disconnected to the surface water supply reach aquifer; (6) soil macropores disconnected to the surface water supply reach surface soil layer; (7) soil macropores disconnected to the surface water supply reach interface layer; (8) soil macropores disconnected to the surface water supply reach groundwater; (9)soil macropores distributed in interface layer; (10)soil macropores from interface layer to aquifer; (11) soil macropores from aquifer to groundwater).

physical and chemical characteristics (Conte and Ferro 2018). Masselink et al. (2017) concluded that soil water content negatively influence soil macropores connectivity.

Knowledge of soil macropore connectivity is beneficial for understanding ecological and hydrological functions of soils, such as transfer of substances and energy entering the soils, sorption of substances by soils, changes of chemical composition of groundwater, and regulation of water balance of landscapes (Zhang et al. 2017b). Soil macropores connectivity is directly implicated with groundwater discharge, waste disposal risk assessment, and heavy metal redistribution in soils (Beven and Germann 2013; Villamizar and Brown 2017). Despite the importance of soil macropores connectivity for environmental water quality, there are few studies that characterize soil macropore connectivity at larger scales (Hussain et al. 2019).

\section{Soil matrix connectivity}

Soil matrix is heterogeneous due to its physicochemical properties. The location of soil microbial communities within the soil matrix can influence their activity, survival, and persistence during harsh environmental conditions (Gupta and Roper 2010). Undoubtedly, the morphological and surface chemical adjustments of extracellular polymeric substances alter the characteristics of the soil matrix and water flow within it (Morales et al. 2010). Water flow in soil matrix is important for redistributing the precipitation input and enhancing water storage in soils in arid and semi-arid areas (Wu et al. 2017). Water flow in soil matrix is controlled by the soil matrix capillary actions and is addressed with Philips sorptivity concept (Zhang et al. 2017a). Quantifying water flow in soil matrix is highly important in partitioning water infiltrating through the soil matrix. Root systems contribute more to water flow in soil matrix mechanics because they form spatial voids which can be treated as soil matrix flow paths (Gish et al. 1998). Channels formed by root systems may be a major contributor to soil matrix flow (Bogner et al. 2010; Germann et al. 2012).

Interconnected pores within the soil matrix can increase pores connectivity. Although few large soil pores within the soil matrix exist, some works indicate that those medium or small pores can promote water flow effectively when large soil pores connectivity is decreased or soil pores are not connected at all (Larsbo et al. 2014; Müller et al. 2018). It is notably known that water flow in soil matrix could be neglected and could not affect the soil moisture dynamics in the short time. However, water flow in soil matrix could be connected with the surrounding water flow to affect soil water in the long run. Water flow in soil matrix can have a positive impact on groundwater quality (Wu et al. 2017).

\section{Soil macropores-matrix connectivity}

Soil macropores-matrix connectivity occurs in particular when flow paths end at a certain depth (Fig. 8) (Backnäs et al. 2012; Beven 2018). Higher soil macropores-matrix connectivity also occurs in soils with coarse soil texture and high soil organic matter content (Alaoui et al. 2011; Backnäs et al. 2012). This connectivity can affect water and mass transfer (Laine-Kaulio et al. 2014; Williams et al. 2016). For example, an increase of water content in soil matrix may activate soil macropores that are not connected to the surface water supply (Faúndez Urbina et al. 2019). Soil macropores-matrix connectivity is greatly influenced by soil physicochemical characteristics (Weiler and Naef 2003). A higher connectivity is more related with better permeability of the matrix zones and also related with lower soil water content in soils. However, a lower connectivity is indicated due to the small permeability of the compacted matrix zones and also due to the saturation 
of the matrix zones (Weiler and Naef 2003). Low connectivity and high permeability of soils may lead to high water flow in soil macropores, while water flow in soil macropores will decrease and soil macropores will become saturated when low connectivity and permeability of soils occur (Weiler and Naef 2003).

Soil macropores-matrix connectivity is an important component of connectivity. When the low connectivity and the high permeability of bedrocks occur, water flow mainly passes through soil profiles through soil macropores. However, when the low connectivity and the low permeability of bedrocks occur, water saturation is generally promising in soil macropores (Weiler and Naef 2003). For example, the connectivity is enhanced, which results in the increase of water transfer between soil macropores and soil matrix. However, the connectivity is lower, and water transfer is not significant which leads to more effluent from soil macropores (Ghafoor et al. 2013; Larsbo et al. 2014; Soares et al. 2015). It requires more time to balance the hydraulic pressure between the two zones as the connectivity is lower. Water transfer between the two zones increases which leads to lower time to balance the hydraulic pressure as the connectivity is higher (Larsbo et al. 2014). In general, inertia force is larger than viscous force in soil macropores because of the high hydraulic conductivity and high permeability of soil macropores, while better reservoir ability within the soil matrix occurs due to the low hydraulic conductivity in the matrix zones. Water flow in soil matrix can hydrologically connect with water flow in soil macropores eventually though the water flow distance in the matrix zones is relatively short (Weiler and Naef 2003). Larger soil macropores with more continuity, less tortuosity, and more widely space may result in potentially faster flow, especially weaker connectivity with soil matrix than in smaller soil macropores (Jarvis 2007; Backnäs et al. 2012).

\section{Future trends on hydrological connectivity}

Over the long-term, hydrological connectivity has been developed to guide hydrologists in better understanding its importance for water quantity and quality. However, we must realize that this long-term purpose could not be achieved because our understanding on hydrological connectivity is rather a starting point. Despite the general increase of the emphasis on hydrological connectivity, there is still some missing for hydrologists. This study has raised some future trends on the knowledge that is lost or is in danger of being lost. In-depth assessments of hydrological connectivity future challenges, broadly defined, are on the following topics but not limited to. Throughout our discussions on hydrological connectivity, we have focused on the common viewpoints that provide more information to reduce the controversy of hydrological connectivity studies to a great extent.
Firstly, we should effectively define the state of connectivity and disconnectivity between different landscape units both in space and time using a range of approaches. Both connectivity and disconnectivity are related with ecohydrological responses at a certain condition. Researchers can promote hydrological connectivity as a desirable landscape characteristic and avoid labeling disconnectivity as a condition. However, we realize that disconnectivity as geomorphic characteristic occurs within landscapes. Disconnectivity can form some environmental and social benefits including nutrient retention which increases species abundance, biotic uptake which improves water quality, and hydrological fluxes attenuation which reduces flood risks (Wohl et al. 2019). In future trends, people should adopt a range of promising numerical modeling and approach to characterize the state of hydrological connectivity to decide how, when, and where connectivity should be considered.

Secondly, over the past years, geomorphological systems have been used in hydrological sciences to define hydrological connectivity. Future studies using network theory should be combined with automated unsupervised classification methods (Masselink et al. 2017). Meanwhile, the use of dynamic networks could also provide more potential information for the quantification of hydrological connectivity within landscapes (Heckmann et al. 2015). The findings of recent work conclude that there are uncertainties concerning the influences of roads networks in forest, agriculture, wetland, pasture, and residential areas on the degree of hydrological connectivity at the watershed scale. In particular, the function of ditch networks should be suggested as a component of hydrological connectivity to improve water quality in different land use media.

Thirdly, human impacts have been modifying the landscape units, such as altering the land use, regulating the flow of water and substances, and causing the change of geomorphological systems. Positive or negative humanity exerts different influences on hydrological connectivity. It is still unclear on how to assess and distinguish the effects of natural and anthropic hydrological connectivity on ecohydrological responses. The effects of changing climate dynamics of hydrological connectivity on hydrological, biological, and biogeochemical responses remain a gap in our recent works with the high variation in climate. In particular, hydrological connectivity linked to social-economical-ecological-hydrological frameworks involving coordinated trans-, multi-, inter-, and separate disciplinary is required (Owens 2020). The interdisciplinary nature of the water-energy-food-forest nexus should also be assessed when people characterize the effects of hydrological connectivity (Melo et al. 2021).

Finally, there are concerns that COVID-19 may never go away and that we will have to get used to living with COVID19 (Sivakumar 2021). This means that our demands for water sources will significantly increase in the future. COVID-19 
will have serious impacts on water quantity and quality (Sivakumar 2020). For example, the presence of COVID-19 in the sewage stool leading to groundwater contamination can be an emerging threat to the groundwater quality and can also lead to the spread of COVID-19 (Huo et al. 2021). How to effectively manage the connections between surface water and groundwater to prevent the spread of COVID-19 remains unclear. In particular, some studies showed that climate changes, such as rising temperature and relative humidity, have extremely ambiguous effects on COVID-19 (Amnuaylojaroen and Parasin 2021). Climate change can worsen COVID-19 pandemic occurring in the future (Fan et al. 2021; Mehmood et al. 2021). Climate change can also significantly influence the state of hydrological connectivity. How to define the link between COVID-19 and the water-energy-food-forest nexus considering the concepts of hydrological connectivity should be resolved (Durodola et al. 2020).

\section{Conclusions}

Through a summary of published papers on this thesis, we sought to explore hydrological connectivity and its links with ecohydrology. These findings proposed a synthesis to develop insights on water quantity and quality. Reported records showed that the development of hydrological connectivity is temporally promising since 2003 . We cannot define a standard concept of hydrological connectivity that works in all environments. We desire to show different concepts of hydrological connectivity in different environment. The degree and nature of hydrological connectivity are not static due to the influences of human activities and changes of natural factors. The index of hydrological connectivity and simulating models are the most significant approaches to assess the changes in hydrological connectivity. Future trends, particularly assessing the influences of climate changes on hydrological connectivity as well as COVID-19 pandemic, should be discussed in depth. This study provides new information and development of hydrological connectivity so as to prevent its negative impacts on surface or subsurface water quantity and quality, and understanding hydrological connectivity is also beneficial for sound water sources management.

Acknowledgements The first author (Yinghu Zhang) is grateful to the National Natural Science Foundation of China for financial support. Chenyang Huang, Wenqi Zhang, Jinhong Chen, and Lu Wang are appreciated for their help during references checking. We are highly thankful to the anonymous reviewers and editors for their careful reading and insightful comments and suggestions on our manuscript.

Author contribution Yinghu Zhang: writing original draft, review, data collection and analysis; Chenyang Huang, Wenqi Zhang, Jinhong Chen, and $\mathrm{Lu}$ Wang: editing and critical revision of the article.
Funding This research was supported by the National Natural Science Foundation of China (41907007), Jiangsu Province Natural Science Foundation for Youth (BK20190747), and the National Natural Science Foundation of China (41771547).

Data availability Not applicable (the data used is presented in various figures in this article)

\section{Declarations}

Ethics approval Not applicable

Consent to participate Not applicable

Consent for publication Not applicable

Competing interests The authors declare no competing interests.

\section{References}

Addy S, Wilkinson ME (2021) Embankment lowering and natural selfrecovery improves river-floodplain hydro-geomorphic connectivity of a gravel bed river. Sci Total Environ 770:144126

Alaoui A, Caduff U, Gerke HH, Weingartner R (2011) Preferential flow effects on infiltration and runoff in grassland and forest soils. Vadose Zone J 10:367-377

Ali GA, Roy AG (2010) Shopping for hydrologically representative connectivity metrics in a humid temperate forested catchment. Water Resour Res 46:W12544

Ameli AA, Creed IF (2017) Quantifying hydrologic connectivity of wetlands to surface water systems. Hydrol Earth Syst Sci 21(3):17911808

Amnuaylojaroen T, Parasin N (2021) The association between covid-19, air pollution, and climate change. Front Public Health 9:662499

Antoine M, Javaux M, Bielders C (2009) What indicators can capture runoff-relevant connectivity properties of the micro-topography at the plot scale? Adv Water Resour 32(8):1297-1310

Appels WM, Bogaart PW, van der Zee SE (2011) Influence of spatial variations of microtopography and infiltration on surface runoff and field scale hydrological connectivity. Adv Water Resour 34(2):303313

Appels WM, Bogaart PW, van der Zee SEATM (2016) Surface runoff in flat terrain: how field topography and runoff generating processes control hydrological connectivity. J Hydrol 534:493-504

Backnäs S, Laine-Kaulio H, Kløve B (2012) Phosphorus forms and related soil chemistry in preferential flowpaths and the soil matrix of a forested podzolic till soil profile. Geoderma 189-190:50-64

Banks EW, Brunner P, Simmons CT (2011) Vegetation controls on variably saturated processes between surface water and groundwater and their impact on the state of connection. Water Resour Res 47(11):178-186

Barbarossa V, Schmitt R, Huijbregts M et al (2020) Impacts of current and future large dams on the geographic range connectivity of freshwater fish worldwide. Proc Natl Acad Sci 117(7):201912776

Beven K (2018) A century of denial: preferential and nonequilibrium water flow in soils, 1864-1984. Vadose Zone J 17:180153

Beven K, Germann P (1982) Macropores and water flow in soils. Water Resour Res 18(5):1311-1325

Beven K, Germann P (2013) Macropores and water flow in soils revisited. Water Resour Res 49(6):3071-3092

Birkel C, Tetzlaff D, Dunn SM et al (2010) Towards a simple dynamic process conceptualization in rainfall-runoff models using multi- 
criteria calibration and tracers in temperate, upland catchments. Hydrol Process 24(3):260-275

Blume T, Meerveld HV (2015) From hillslope to stream: methods to investigate subsurface connectivity. Wiley Interdiscip Rev Water 2(3): 177-198

Bogner C, Gaul D, Kolb A, Schmiedinger I, Huwe B (2010) Investigating flow mechanisms in a forest soil by mixed-effects modelling. Eur J Soil Sci 61(6):1079-1090

Borges JAR, Pires LF, Cássaro FAM, Auler AC, Rosa JA, Heck RJ, Roque WL (2019) X-ray computed tomography for assessing the effect of tillage systems on topsoil morphological attributes. Soil Tillage Res 189:25-35

Borselli L, Cassi P, Torri D (2008) Prolegomena to sediment and flow connectivity in the landscape: a GIS and field numerical assessment. Catena 75:268-277

Bracken LJ, Croke J (2007) The concept of hydrological connectivity and its contribution to understanding runoff-dominated geomorphic systems. Hydrol Process 21(13):1749-1763

Bracken LJ, Wainwright J, Ali GA, Tetzlaff D, Smith MW, Reaney SM, Roy AG (2013) Concepts of hydrological connectivity: Research approaches, pathways and future agendas. Earth Sci Rev 119:17-34

Bracken LJ, Turnbull L, Wainwright J, Bogaart P (2015) Sediment connectivity: a framework for understanding sediment transfer at multiple scales. Earth Surf Process Landf 40(2):177-188

Brannen R, Spence C, Ireson A (2015) Influence of shallow groundwatersurface water interactions on the hydrological connectivity and water budget of a wetland complex. Hydrol Process 29(18):3862-3877

Brunner P, Simmons CT, Cook PG (2009) Spatial and temporal aspects of the transition from connection to disconnection between rivers, lakes and groundwater. J Hydrol 376(1-2):159-169

Callow JN, Smettem K (2009) The effect of farm dams and constructed banks on hydrologic connectivity and runoff estimation in agricultural landscapes. Environ Model Softw 24(8):959-968

Cammeraat LH (2002) A review of two strongly contrasting geomorphological systems within the context of scale. Earth Surf Process Landf 27(11):1201-1222

Carucci V, Petitta M, Aravena R (2012) Interaction between shallow and deep aquifers in the tivoli plain (central italy) enhanced by groundwater extraction: a multi-isotope approach and geochemical modeling. Appl Geochem 27(1):266-280

Casanova SMC, Panarelli EA, Henry R (2009) Rotifer abundance, biomass, and secondary production after the recovery of hydrologic connectivity between a river and two marginal lakes (são paulo, brazil). Limnologica 39(4):292-301

Cerdà A (1997) Soil erosion after land abandonment in a semiarid environment of southeastern Spain. Arid Soil Res Rehabil 11(2):163176

Chen X, Wang D (2015) Modeling seasonal surface runoff and base flow based on the generalized proportionality hypothesis. J Hydrol 527: 367-379

Chen X, Chen L, Stone MC, Acharya K (2020) Assessing connectivity between the river channel and floodplains during high flows using hydrodynamic modeling and particle tracking analysis. J Hydrol 583:124609

Chi S, Zheng J, Zhao X et al (2016) Macroinvertebrate communities and the relationships with biotic factors in river-connected lakes in the lower reaches of Yangtze river, China. Environ Monit Assess 188(10):577.1-577.12

Chiasson-Poirier G, Franssen J, Lafrenière MJ, Fortier D, Lamoureux SF (2020) Seasonal evolution of active layer thaw depth and hillslopestream connectivity in a permafrost watershed. Water Resour Res 56(1):WR025828

Chu X, Yang J, Chi Y, Zhang J (2013) Dynamic puddle delineation and modeling of puddle-to-puddle filling-spilling-merging-splitting overland flow processes. Water Resour Res 49(6):3825-3829
Collins SL, Loveless SE, Muddu S et al (2020) Groundwater connectivity of a sheared gneiss aquifer in the Cauvery River basin, India. Hydrogeol J 28:1371-1388

Conte P, Ferro V (2018) Measuring hydrological connectivity inside a soil by low field nuclear magnetic resonance relaxometry. Hydrol Process 32(1):93-101

Covino T (2017) Hydrologic connectivity as a framework for understanding biogeochemical flux through watersheds and along fluvial networks. Geomorphology. 277:133-144

Cui G, Liu Y, Tong S (2021) Analysis of the causes of wetland landscape patterns and hydrological connectivity changes in momoge national nature reserve based on the Google earth engine platform. Arab J Geosci 14:170

Deng X, Xu Y, Han L (2018) Impacts of human activities on the structural and functional connectivity of a river network in the Taihu plain. Land Degrad Dev 29:2575-2588

Dong R, Wang Y, Lu C, Lei G, Wen L (2021) The seasonality of macroinvertebrate $\beta$ diversity along the gradient of hydrological connectivity in a dynamic river-floodplain system. Ecol Indic 121: 107112

Dor N, Syafalni S, Abustan I, Rahman MTA, Nazri MAA, Mostafa R, Mejus L (2011) Verification of surface-groundwater connectivity in an irrigation canal using geophysical, water balance and stable isotope approaches. Water Resour Manag 25(11):2837-2853

Durodola OS, Nabunya V, Kironde MS et al (2020) Covid-19 and the water-energy-food nexus in africa: evidence from nigeria, uganda, and tanzania. World Water Policy 6:176-201

Erban LE, Gorelick SM, Zebker HA (2014) Groundwater extraction, land subsidence, and sea-level rise in the Mekong delta, Vietnam. Environ Res Lett 9(8):084010

Fan JL, Da Y, Zeng B et al (2021) How do weather and climate change impact the covid-19 pandemic? evidence from the Chinese mainland. Environ Res Lett 16(1):014026

Faúndez Urbina CA, Dam JCV, Hendriks RFA et al (2019) Water flow in soils with heterogeneous macropore geometries. Vadose Zone J 18: 190015

Fishkis O, Noell U, Diehl L, Jaquemotte J, Lamparter A, Stange CF, Burke V, Koeniger P, Stadler S (2020) Multitracer irrigation experiment for assessing the relevance of preferential flow for nonsorbing solute transport in agricultural soils. Geoderma 371:114386

Freeman MC, Pringle CM, Jackson CR (2007) Hydrologic connectivity and the contribution of stream headwaters to ecological integrity at regional scales. J Am Water Resour Assoc 43(1):5-14

Fullerton AH, Burnett KM, Steel EA et al (2010) Hydrological connectivity for riverine fish: measurement challenges and research opportunities. Freshw Biol 55:2215-2237

Germann PF, Lange B, Lüscher P (2012) Preferential Flow Dynamics and Plant Rooting Systems. In Hydropedology (pp. 121-141). Elsevier. https://doi.org/10.1016/B978-0-12-386941-8.00004-6

Ghafoor A, Koestel J, Larsbo M, Moeys J, Jarvis N (2013) Soil properties and susceptibility to preferential solute transport in tilled topsoil at the catchment scale. J Hydrol 492:190-199

Gish TJ, Gimenez D, Rawls WJ (1998) Impact of roots on ground water quality. Plant Soil 200(1):47-54

Gleeson T, Vandersteen J, Sophocleous MA et al (2010) Groundwater sustainability strategies. Nat Geosci 3(6):378-379

Gleeson T, Befus KM, Jasechko S, Luijendijk E, Cardenas MB (2016) The global volume and distribution of modern groundwater. Nat Geosci 9(2):161-167

Golden HE, Lane CR, Amatya DM, Bandilla KW, Raanan Kiperwas H, Knightes CD, Ssegane H (2014) Hydrologic connectivity between geographically isolated wetlands and surface water systems: a review of select modeling methods. Environ Model Softw 53:190 206 
Gomi T, Sidle RC, Miyata S et al (2008) Dynamic runoff connectivity of overland flow on steep forested hillslopes: scale effects and runoff transfer. Water Resour Res 44(8):2493-2503

Good SP, Noone D, Bowen G (2015) Hydrologic connectivity constrains partitioning of global terrestrial water fluxes. Science 349(6244): 175-177

Grayson RB, Western AW, Chiew FHS (1997) Preferred states in spatial soil moisture patterns: local and nonlocal controls. Water Resour Res 22:1786-1897

Gupta VVSR, Roper MM (2010) Protection of free-living nitrogen-fixing bacteria within the soil matrix. Soil Tillage Res 109(1):50-54

Hall CJ, Jordaan A, Frisk MG (2011) The historic influence of dams on diadromous fish habitat with a focus on river herring and hydrologic longitudinal connectivity. Landsc Ecol 26(1):95-107

Heckmann T, Schwanghart W, Phillips JD (2015) Graph theory-recent developments of its application in geomorphology. Geomorphology 243:130-146

Hendrickx JMH, Flury M (2001) Uniform and preferential flow mechanisms in the vadose zone. In: Conceptual Models of Flow and Transport in the Fractured Vadose Zone, pp 149-187. National Research Council, National Academy Press, Washington, DC.

Hitt NP, Angermeier PL (2008) River-stream connectivity affects fish bioassessment performance. Environ Manag 42(1):132-150

Hokanson KJ, Lukenbach MC, Devito KJ, Kettridge N, Petrone RM, Waddington JM (2016) Groundwater connectivity controls peat burn severity in the boreal plains. Ecohydrology 9:574-584

Hu J, Chi S, Hu J (2019a) An attempt to measure longitudinal connectivity based on the community structure of phytoplankton. Environ Monit Assess 191(6):382

Hu X, Li XY, Wang P, Liu Y, Wu XC, Li ZC, Zhao YD, Cheng YQ, Guo LL, Lyu YL, Liu LY (2019b) Influence of exclosure on CTmeasured soil macropores and root architecture in a shrubencroached grassland in northern China. Soil Tillage Res 187:21-30

Huang H, Chen Z, Wang T, Zhang L, Liu T, Zhou G (2021) Pattern and degree of groundwater recharge from river leakage in a karst canyon area under intensive mine dewatering. Sci Total Environ 774(6): 144921

Hueso-González P, Ruiz-Sinoga JD, Martínez-Murillo JF, Lavee H (2015) Overland flow generation mechanisms affected by topsoil treatment: application to soil conservation. Geomorphology 228: 796-804

Huo CH, Dar AA, Nawaz A et al (2021) Groundwater contamination with the threat of COVID-19: Insights into CSR theory of Carroll's pyramid. J King Saud Univ Sci 33(2):101295

Hussain SI, Frey SK, Blowes DW, Ptacek CJ, Wilson D, Mayer KU, Su D, Gottschall N, Edwards M, Lapen DR (2019) Reactive transport of manure-derived nitrogen in the vadose zone: consideration of macropore connectivity to subsurface receptors. Vadose Zone J 18(1):1-18

Ivkovic KM (2009) A top-down approach to characterise aquifer-river interaction processes. J Hydrol 365(3-4):145-155

James AL, Roulet NT (2007) Investigating hydrologic connectivity and its association with threshold change in runoff response in a temperate forested watershed. Hydrol Process 21(25):3391-3408

Jarvis NJ (2007) A review of non-equilibrium water flow and solute transport in soil macropores: principles, controlling factors and consequences for water quality. Eur J Soil Sci 58(3):523-546

Jarvis N, Larsbo M, Koestel J (2017) Connectivity and percolation of structural pore networks in a cultivated silt loam soil quantified by X-ray tomography. Geoderma 287:71-79

Jencso KG, McGlynn BL, Gooseff MN et al (2010) Hillslope hydrologic connectivity controls riparian groundwater turnover:implications of catchment structure for riparian buffering and stream water sources. Water Resour Res 46:W10524

Karim F, Dutta D, Marvanek S, Petheram C, Ticehurst C, Lerat J, Kim S, Yang A (2015) Assessing the impacts of climate change and dams on floodplain inundation and wetland connectivity in the wet-dry tropics of northern Australia. J Hydrol 522:80-94

Karim F, Petheram C, Marvanek T et al (2016) Impact of climate change on floodplain inundation and hydrological connectivity between wetlands and rivers in a tropical river catchment. Hydrol Process 30(10):1574-1593

Kath J, Boulton AJ, Harrison ET, Dyer FJ (2018) A conceptual framework for ecological responses to groundwater regime alteration (fergra). Ecohydrology 11:e2010

Katuwal S, Norgaard T, Moldrup P et al (2015) Linking air and water transport in intact soils to macropore characteristics inferred from $\mathrm{X}$ ray computed tomography. Geoderma 237:9-20

Knudby C, Carrera J (2005) On the relationship between indicators of geostatistical, flow and transport connectivity. Adv Water Resour 28(4):405-421

Koestel JK, Norgaard T, Luong NM, Vendelboe AL, Moldrup P, Jarvis NJ, Lamandé M, Iversen BV, Wollesen de Jonge L (2013) Links between soil properties and steady-state solute transport through cultivated topsoil at the field scale. Water Resour Res 49(2):790 807

Kompanizare M, Petrone RM, Shafii M, Robinson DT, Rooney RC (2018) Effect of climate change and mining on hydrological connectivity of surficial layers in the Athabasca oil sands region. Hydrol Process 32(25):3698-3716

Laine-Kaulio H, Backnäs S, Karvonen T, Koivusalo H, McDonnell JJ (2014) Lateral subsurface stormflow and solute transport in a forested hillslope: a combined measurement and modeling approach. Water Resour Res 50(10):8159-8178

Lane SN, Reaney SM, Heathwaite AL (2009) Representation of landscape hydrological connectivity using a topographically driven surface flow index. Water Resour Res 45:W08423

Lapworth DJ, Dochartaigh B, Nair T et al (2021) Characterising groundwater-surface water connectivity in the lower Gandak catchment, a barrage regulated biodiversity hotspot in the mid-Gangetic basin. J Hydrol 594:125923

Larsbo M, Koestel J, Jarvis N (2014) Relations between macropore network characteristics and the degree of preferential solute transport. Hydrol Earth Syst Sci 18(18):5255-5269

Larsen LG, Ma J, Kaplan D (2017) How important is connectivity for surface water fluxes? A generalized expression for flow through heterogeneous landscapes. Geophys Res Lett 44(20):10-349

Lesschen JP, Schoorl JM, Cammeraat LH (2009) Modelling runoff and erosion for a semi-arid catchment using a multi-scale approach based on hydrological connectivity. Geomorphology 109(3):174 183

Lexartza-Artza I, Wainwright J (2009) Hydrological connectivity: linking concepts with practical implications. Catena 79(2):146-152

Li Z, Lin X, Coles AE, Chen X (2017) Catchment-scale surface watergroundwater connectivity on china's loess plateau. Catena 152:268 276

Liu Y, Cui B, Du J et al (2020) A method for evaluating the longitudinal functional connectivity of a river-lake-marsh system and its application in China. Hydrol Process 34:5278-5297

López-Vicente M, Álvarez S (2018) Influence of dem resolution on modelling hydrological connectivity in a complex agricultural catchment with woody crops. Earth Surf Process Landf 43:14031415

López-Vicente M, Navas A, Gaspar L, Machín J (2013) Advanced modelling of runoff and soil redistribution for agricultural systems: the SERT model. Agric Water Manag 125:1-12

Lu W, Lei H, Yang D, Tang L, Miao Q (2018) Quantifying the impacts of small dam construction on hydrological alterations in the Jiulong river basin of southeast china. J Hydrol 567:382-392

Ma L, Shao M, Fan J et al (2021) Effects of earthworm (metaphire guillelmi) density on soil macropore and soil water content in typical anthrosol soil. Agric Ecosyst Environ 311(5):107338 
Markstrom S, Niswonger R, Regan R, Prudic D, Barlow P (2008) GSFlow-coupled ground-water and surface-water flow model based on the integration of the precipitation-runoff modeling system (PRMS) and the modular ground-water flow model (Modflow2005), U.S. Geol. Surv. Tech. Methods, 6-d1, Reston, Va., pp 240

Martinez JL, Raiber M, Cox ME (2015) Assessment of groundwatersurface water interaction using long-term hydrochemical data and isotope hydrology: headwaters of the Condamine River, Southeast Queensland, Australia. Sci Total Environ 536:499-516

Masselink RJ, Heckmann T, Temme AJ et al (2017) A network theory approach for a better understanding of overland flow connectivity. Hydrol Process 31(1):207-220

Mayor AG, Bautista S, Rodriguez F, Kéfi S (2019) Connectivitymediated ecohydrological feedbacks and regime shifts in drylands. Ecosystems 22(7):1497-1511

Mcguire KJ, Mcdonnell JJ (2010) Hydrological connectivity of hillslopes and streams: characteristic time scales and nonlinearities. Water Resour Res 46:W10543

Mcnamara JP, Chandler D, Seyfried M et al (2005) Soil moisture states, lateral flow, and streamflow generation in a semi-arid, snowmeltdriven catchment. Hydrol Process 19(20):4023-4038

Meerkerk AL, Wesemael BV, Bellin N (2009) Application of connectivity theory to model the impact of terrace failure on runoff in semiarid catchments. Hydrol Process 23(19):2792-2803

Mehmood K, Bao Y, Abrar MM, Petropoulos GP, Saifullah, Soban A, Saud S, Khan ZA, Khan SM, Fahad S (2021) Spatiotemporal variability of covid-19 pandemic in relation to air pollution, climate and socioeconomic factors in pakistan. Chemosphere 271(4):129584

Meier W, Bonjour C, Wüest A, Reichert P (2003) Modeling the effect of water diversion on the temperature of mountain streams. J Environ Eng 129(8): 755-764

Melo FPL, Parry L, Brancalion PHS, Pinto SRR, Freitas J, Manhães AP, Meli P, Ganade G, Chazdon RL (2021) Adding forests to the waterenergy-food nexus. Nature Sustainability 4:85-92

Miranda LE (2005) Fish assemblages in oxbow lakes relative to connectivity with the mississippi river. Trans Am Fish Soc 134(6):1480 1489

Molina A, Govers G, An V et al (2009) Assessing the reduction of the hydrological connectivity of gully systems through vegetation restoration: field experiments and numerical modelling. Hydrol Earth Syst Sci 13(10):1823-1836

Morales VL, Parlange JY, Steenhuis TS (2010) Are preferential flow paths perpetuated by microbial activity in the soil matrix? A review. J Hydrol 393(1-2):29-36

Müller K, Katuwal S, Young I, McLeod M, Moldrup P, de Jonge LW, Clothier B (2018) Characterising and linking X-ray CT derived macroporosity parameters to infiltration in soils with contrasting structures. Geoderma 313:82-91

Naveed M, Moldrup P, Schaap M et al (2016) Macropore flow at the field scale: predictive performance of empirical models and X-ray CT analyzed macropore characteristics. Hydrol Earth Syst Sci 12(11): 12089-12120

Neff BP, Rosenberry DO (2018) Groundwater connectivity of uplandembedded wetlands in the prairie pothole region. Wetlands $38(1)$ : $51-63$

Nilsson C, Reidy CA, Dynesius M, et al (2005) Fragmentation and flow regulation of the world's large river systems. Science 308:405

Nimmo JR (2021) The processes of preferential flow in the unsaturated zone. Soil Sci Soc Am J 85(1):1-27

Ortíz-Rodríguez AJ, Borselli L, Sarocchi D (2017) Flow connectivity in active volcanic areas: use of index of connectivity in the assessment of lateral flow contribution to main streams. Catena 157:90-111

Owens PN (2020) Soil erosion and sediment dynamics in the anthropocene: a review of human impacts during a period of rapid global environmental change. J Soils Sediments 20(12):1-29
Pekel JF, Cottam A, Gorelick N, Belward AS (2016) High-resolution mapping of global surface water and its long-term changes. Nature 540:418-422

Pittman F, Mohammed A, Cey E (2020) Effects of antecedent moisture and macroporosity on infiltration and water flow in frozen soil. Hydrol Process 34:795-809

Posthumus H, Hewett C, Morris J et al (2008) Agricultural land use and flood risk management: engaging with stakeholders in north yorkshire. Agric Water Manag 95(7):787-798

Pringle CM (2001) Hydrologic connectivity and the management of biological reserves: a global perspective. Ecol Appl 11(4):981-998

Pringle CM (2003) What is hydrologic connectivity and why is it ecologically important? Hydrol Process 17(13):2685-2689

Rassam DW, Peeters L, Pickett T, Jolly I, Holz L (2013) Accounting for surface-groundwater interactions and their uncertainty in river and groundwater models: a case study in the Namoi River, Australia. Environ Model Softw 50:108-119

Reaney SM, Bracken LJ, Kirkby MJ (2014) The importance of surface controls on overland flow connectivity in semi-arid environments: results from a numerical experimental approach. Hydrol Process 28(4):2116-2128

Reid MA, Reid MC, Thoms MC (2016) Ecological significance of hydrological connectivity for wetland plant communities on a dryland floodplain river, Macintyre river, Australia. Aquat Sci 78(1):139 158

Rezanezhad F, Quinton WL, Price JS, Elrick D, Elliot TR, Heck RJ (2009) Examining the effect of pore size distribution and shape on flow through unsaturated peat using computed tomography. Hydrol Earth Syst Sci 13(10):1993-2002

Rugel K, Golladay SW, Jackson CR, et al (2016) Delineating groundwater/surface water interaction in a karst watershed: lower flint river basin, southwestern Georgia, USA. Journal of Hydrology: Regional Studies 5:1-19

Saffarpour S, Western AW, Adams R, McDonnell JJ (2016) Multiple runoff processes and multiple thresholds control agricultural runoff generation. Hydrol Earth Syst Sci 20:4525-4545

Sammartino S, Michel E, Capowiez Y (2012) A novel method to visualize and characterize preferential flow in undisturbed soil cores by using multislice helical CT. Vadose Zone J 11(1):1-13

Sawyer AH, Edmonds DA, Knights D (2015) Surface watergroundwater connectivity in deltaic distributary channel networks. Geophys Res Lett 42:10299-10306

Shao X, Fang Y, Jawitz J et al (2019) River network connectivity and fish diversity. Sci Total Environ 689:21-30

Shao X, Fang Y, Cui B (2020) A model to evaluate spatiotemporal variations of hydrological connectivity on a basin-scale complex river network with intensive human activity. Sci Total Environ 723: 138051

Shentsis I (2010) Increasing transmission losses from flood events due to groundwater extraction. Hydrol Process 17(4):713-725

Sivakumar B (2021) Covid-19 and water. Stoch Env Res Risk A 35:531534

Smith MW, Bracken LJ, Cox NJ (2010) Toward a dynamic representation of hydrological connectivity at the hillslope scale in semiarid areas. Water Resour Res 46(12):65-74

Soares A, Moldrup P, Vendelboe AL, Katuwal S, Norgaard T, DelerueMatos C, Tuller M, de Jonge LW (2015) Effects of soil compaction and organic carbon content on preferential flow in loamy field soils. Soil Sci 180(1):10-20

Soracco CG, Villarreal R, Melani EM et al (2019) Hydraulic conductivity and pore connectivity. Effects of conventional and no-till systems determined using a simple laboratory device. Geoderma 337:12361244

Sougnez N, van Wesemael B, Vanacker V (2011) Low erosion rates measured for steep, sparsely vegetated catchments in southeast Spain. Catena 84:1-11 
Stieglitz M, Shaman J, Mcnamara J et al (2003) An approach to understanding hydrologic connectivity on the hillslope and the implications for nutrient transport. Glob Biogeochem Cycles 17(4):1-16

Sun C, Chen L, Zhu H, Xie H, Qi S, Shen Z (2021) New framework for natural-artificial transport paths and hydrological connectivity analysis in an agriculture-intensive catchment. Water Res 196(5): 117015

Tague CL, Band LE (2001) Evaluating explicit and implicit routing for watershed hydro-ecological models of forest hydrology at the small catchment scale. Hydrol Process 15(8):1415-1439

Tan Z, Wang X, Chen B, Liu X, Zhang Q (2019) Surface water connectivity of seasonal isolated lakes in a dynamic lake-floodplain system. J Hydrol 579:124154

Tan Z, Li Y, Zhang Q, Liu X, Song Y, Xue C, Lu J (2021) Assessing effective hydrological connectivity for floodplains with a framework integrating habitat suitability and sediment suspension behavior. Water Res 201:117253

Tesemma ZK, Wei Y, Peel MC, Western AW (2015) The effect of yearto-year variability of leaf area index on variable infiltration capacity model performance and simulation of runoff. Adv Water Resour 83(9):310-322

Tetzlaff D, Soulsby C, Bacon PJ, Youngson AF, Gibbins C, Malcolm IA (2007) Connectivity between landscapes and riverscapes-a unifying theme in integrating hydrology and ecology in catchment science? Hydrol Process 21(10):1385-1389

Trigg MA, Michaelides K, Neal JC, Bates PD (2013) Surface water connectivity dynamics of a large scale extreme flood. J Hydrol 505:138-149

Turnbull L, Wainwright J, Brazier RE (2008) A conceptual framework for understanding semi-arid land degradation: ecohydrological interactions across multiple-space and time scales. Ecohydrology 1(1): 23-34

Van de Meutter F, Stoks R, de Meester L (2006) Rapid response of macroinvertebrates to drainage management of shallow connected lakes. J Appl Ecol 43(1):51-60

Villamizar ML, Brown CD (2017) A modelling framework to simulate river flow and pesticide loss via preferential flow at the catchment scale. Catena 149:120-130

Vivancos A, Górski K, Manosalva A, Toledo B, Reid M, Habit E (2021) Hydrological connectivity drives longitudinal movement of endangered endemic Chilean darter Percilia irwini (Eigenmann, 1927). J Fish Biol 98(1):33-43

Vogel HJ, Roth K (2003) Moving through scales of flow and transport in soil. J Hydrol 272(1-4):95-106

Von Freyberg J, Radny D, Gall HE et al (2014) Implications of hydrologic connectivity between hillslopes and riparian zones on streamflow composition. J Contam Hydrol 169:62-74

Wang D, Wang X, Huang Y et al (2021a) Impact analysis of small hydropower construction on river connectivity on the upper reaches of the great rivers in the Tibetan plateau. Glob Ecol Conserv 4: e01496

Wang N, Chu X, Zhang X (2021b) Functionalities of surface depressions in runoff routing and hydrologic connectivity modeling. J Hydrol 593:125870

Ward JV, Stanford JA (1995) The serial discontinuity concept: extending the model to floodplain rivers. Regul Rivers: Res Manag 10:159168

Watanabe K, Kugisaki Y (2017) Effect of macropores on soil freezing and thawing with infiltration. Hydrol Process 31(2):270-278
Weiler M, Naef F (2003) An experimental tracer study of the role of macropores in infiltration in grassland soils. Hydrol Process 17(2): 477-493

Western AW, Blöschl G, Grayson RB (2001) Toward capturing hydrologically significant connectivity in spatial patterns. Water Resour Res 37(1):83-97

Williams MR, King KW, Ford W, Buda AR, Kennedy CD (2016) Effect of tillage on macropore flow and phosphorus transport to tile drains. Water Resour Res 52(4):2868-2882

Wilson C, Kampf SK, Ryan S et al (2021) Connectivity of post-fire runoff and sediment from nested hillslopes and watersheds. Hydrol Process 35:e13975

Wohl E, Brierley G, Cadol D, Coulthard TJ, Covino T, Fryirs KA, Grant G, Hilton RG, Lane SN, Magilligan FJ, Meitzen KM, Passalacqua P, Poeppl RE, Rathburn SL, Sklar LS (2019) Connectivity as an emergent property of geomorphic systems. Earth Surf Process Landf 44(1):4-26

Wu GL, Liu Y, Yang Z, Cui Z, Deng L, Chang XF, Shi ZH (2017) Root channels to indicate the increase in soil matrix water infiltration capacity of arid reclaimed mine soils. J Hydrol 546:133-139

Xia S, Liu Y, Wang Y, Chen B, Jia Y, Liu G, Yu X, Wen L (2016) Wintering waterbirds in a large river floodplain: hydrological connectivity is the key for reconciling development and conservation. Sci Total Environ 573:645-660

Xie T, Wang Q, Ning Z et al (2021) Artificial modification on lateral hydrological connectivity promotes range expansion of invasive Spartina alterniflora in salt marshes of the yellow river delta, china. Sci Total Environ 769:144476

Yu M, van der Ploeg M, Ma X et al (2020) Effects of microplastics and earthworm burrows on soil macropore water flow within a laboratory soil column setup. Vadose Zone J 19:e20059

Zhang Y, Niu J, Yu X et al (2015) Effects of fine root length density and root biomass on soil preferential flow in forest ecosystems. Forest Systems 24(1):e012

Zhang Y, Zhang M, Niu J, Zheng H (2016a) The preferential flow of soil: a widespread phenomenon in pedological perspectives. Eurasian Soil Sci 49(6):661-672

Zhang Y, Zhang MX, Niu JZ et al (2016b) Rock fragments and soil hydrological processes: significance and progress. Catena 147: $153-166$

Zhang J, Lei T, Qu L, Chen P, Gao X, Chen C, Yuan L, Zhang M, Su G (2017a) Method to measure soil matrix infiltration in forest soil. J Hydrol 552:241-248

Zhang Y, Niu J, Zhang M, Xiao Z, Zhu W (2017b) Interaction between plant roots and soil water flow in response to preferential flow paths in Northern China. Land Degrad Dev 28:648-663

Zhang Y, Zhang ZM, Ma ZW et al (2018) A review of preferential water flow in soil science. Can J Soil Sci 98(4):604-618

Zhang P, Mao J, Hu T, Dai L, Xu D, Dai H (2020) Water exchange in a large river-lake system: modeling, characteristics and causes. River Res Appl 36(5):697-708

Zuecco G, Rinderer M, Penna D, Borga M, van Meerveld HJ (2019) Quantification of subsurface hydrologic connectivity in four headwater catchments using graph theory. Sci Total Environ 646:12651280

Publisher's note Springer Nature remains neutral with regard to jurisdictional claims in published maps and institutional affiliations. 